OPEN ACCESS

Edited by:

Jaime Romero,

Universidad de Chile, Chile

Reviewed by:

Zhigang Zhou,

Feed Research Institute (CAAS),

China

Foteini Fotios Parlapani,

University of Thessaly, Greece

${ }^{*}$ Correspondence:

M. Carmen Balebona balebona@uma.es

Specialty section:

This article was submitted to

Aquatic Microbiology,

a section of the journal

Frontiers in Microbiology

Received: 05 June 2018 Accepted: 22 January 2019 Published: 07 February 2019

Citation:

Tapia-Paniagua ST, Fumanal M, Anguís V, Fernández-Díaz C, Alarcón FJ, Moriñigo MA and Balebona MC (2019) Modulation of Intestinal Microbiota in Solea senegalensis Fed Low Dietary Level

of Ulva ohnoi.

Front. Microbiol. 10:171. doi: 10.3389/fmicb.2019.00171

\section{Modulation of Intestinal Microbiota in Solea senegalensis Fed Low Dietary Level of Ulva ohnoi}

\author{
Silvana T. Tapia-Paniagua', Milena Fumanal' ${ }^{1}$, Victoria Anguís ${ }^{2}$, \\ Catalina Fernández-Díaz' ${ }^{2}$ F. Javier Alarcón ${ }^{3}$, Miguel A. Moriñigo ${ }^{1}$ and \\ M. Carmen Balebona ${ }^{1 *}$
}

${ }^{1}$ Departamento de Microbiología, Facultad de Ciencias, Universidad de Málaga, Málaga, Spain, ${ }^{2}$ IFAPA Centro El Toruño, El Puerto de Santa María, Spain, ${ }^{3}$ Departamento de Biología y Geología, Universidad de Almería, Almería, Spain

Gastrointestinal (GI) microbiota has a relevant role in animal nutrition, modulation of the immune system and protection against pathogen invasion. Interest in algae as source of nutrients and functional ingredients for aquafeeds is increasing in order to substitute conventional feedstuffs by more sustainable resources. The diet is an important factor in the modulation of the microbiota composition, and functional ingredients have been proposed to shape the microbiota and contribute benefits to the host. However, fish microbiome research is still limited compared to other hosts. Solea senegalensis is a flat fish with high potential for aquaculture in South Europe. In this study, a characterization of the microbiome of $S$. senegalensis (Gl) tract and the effects of feeding Ulva ohnoi supplemented diet has been carried out. Differences in the composition of the microbiota of anterior and posterior sections of $S$. senegalensis Gl tract have been observed, Pseudomonas being more abundant in the anterior sections and Mycoplasmataceae the dominant taxa in the posterior Gl tract sections. In addition, modulation of the GI microbiota of juvenile Senegalese sole fed for 45 days a diet containing low percentage of $U$. ohnoi has been observed in the present study. Microbiota of the anterior regions of the intestinal tract was mainly modulated, with higher abundance of Vibrio spp. in the Gl tract of fish fed dietary U. ohnoi.

Keywords: microbiome, Ulva, algae, high-throughput sequencing, Solea senegalensis

\section{INTRODUCTION}

Fish farming is a growing industry that represents an alternative to fishing. Senegalese sole (Solea senegalensis) is a flatfish with great potential for marine aquaculture due to its high market value and consumer demand. Recent management and technical improvements in S. senegalensis culture are leading to important progress in productivity, but there are still unsolved questions regarding nutrition of this species under cultured conditions (Morais et al., 2016).

In recent years, algae are being considered as potential sources of dietary ingredients for aquafeeds. Among them, Ulva species are a good source of protein, minerals and vitamins, especially vitamin C (Ortiz et al., 2006; Garcia-Casal et al., 2007). In addition, when added to fish meal at low percentages, benefits such as improved growth, feed efficiency, nutrient utilization, and disease resistance have been described in several fish species (Mustafa and Nakagawa, 1995; Wassef et al., 2005; Valente et al., 2006; Ergün et al., 2008; Moutinho et al., 2018). 
In this way, it has been reported that 5\% dietary Ulva can be used as functional ingredient for feeding fish, whilst higher supplementation levels may compromise fish growth (Valente et al., 2006; Moroney et al., 2017). For this reason, experimental feeds for S. senegalensis were supplemented with 5\% Ulva ohnoi in the present work.

It is well established that the gastrointestinal (GI) microbiota has a relevant role in animal nutrition, development and resistance against pathogens (Llewellyn et al., 2014). In the case of fish, several studies have reported the role of GI microbiota in nutrition, epithelial renewal, modulation of immune system and protection from pathogen invasion (Gatesoupe et al., 1997; Rawls et al., 2004; Bates et al., 2006; Salinas et al., 2006; Semova et al., 2012; Ingerslev et al., 2014a,b; Wang et al., 2018). Regarding nutrition, GI microbiota is comprised of a range of microorganisms capable to produce vitamins enzymes such as lipases, amylases, proteases, chitinases and phytases, which contribute to the host digestion through hydrolysis of aquafeed components (Ray et al., 2012). In addition, GI microbiota participate in epithelial renewal and enhancement of $\beta$-catenin stability in enterocytes (Cheesman et al., 2011). Fish GI microbiota is a key component in the development, maturation and modulation of the immune system (Bates et al., 2006). Microbiota and microbiota derived products influence both systemic and mucosal immune response through microbeassociated molecular patterns (MAMPs) interaction with pattern recognition receptors (PRRs) in host cells. Teleost gut-associated lymphoid tissues (GALT) have significant numbers of antigenpresenting cells that participate in the initial stages of the immune response. A role in the modulation of cytokine and immunoglobulin levels as well as activation of cellular response including B and T cells, has been reported for fish GI microbiota (Kelly and Salinas, 2017).

Microbiota composition is shaped by different factors including host species, trophic level, environment, feeding habits (Romero et al., 2014; Eichmiller et al., 2016; Goncalves and Gallardo-Escárate, 2017), probiotics (Merrifield et al., 2010) and functional ingredients or nutraceuticals (Ringø et al., 2006, 2016). Also, variations in physiological parameters along the GI tract have been demonstrated to shape microbial communities (Ye et al., 2014). However, despite some information is already available, fish microbiome research is still limited compared to other hosts.

At present, as in other fish species, inclusion of macroalgae in aquafeeds is being considered for S. senegalensis. However, this species presents important particularities compared to other marine aquaculture species, especially regarding the GI tract (Morais et al., 2016) and, as far as we know, no information about the potential effects of dietary incorporation of Ulva on the GI microbiota is available.

Our current information on the gut microbiota of $S$. senegalensis is in part derived from analysis of culture dependent techniques (Martin-Antonio et al., 2007). However, percentages of culturable bacteria in fish GI tract are under 1\% (Romero and Navarrete, 2006; Navarrete et al., 2009; Aguilera et al., 2013; Romero et al., 2014). Clone libraries based on $16 \mathrm{~S}$ rDNA and denaturing gradient gel electrophoresis (DGGE)
(Tapia-Paniagua et al., 2010) have also been applied to the study of $S$. senegalensis GI microbiota, especially to evaluate the effect of probiotic supplementation of the diet (TapiaPaniagua et al., 2014a). In contrast to previous methodologies, Next Generation Sequencing (NGS) of $16 \mathrm{~S}$ rRNA genes allows unbiased identification of rare, as well as abundant, bacterial members of the gut microbiota. Ghanbari et al. (2015) highlighted the potential of NGS platforms for the analysis of fish gut microbial ecology and its capacity to improve the knowledge of the microbial community profiles of fish GI microbiota. Still, few works have addressed the understanding of the composition and structure of fish GI microbial populations with high throughput sequencing and no studies are available on GI microbiota of S. senegalensis. The knowledge on fish intestinal microbiota will facilitate the development of effective strategies for manipulating GI microbial communities to promote fish health and productivity.

In this study, a characterization of the microbiome of S. senegalensis GI tract was carried out based on 16S rRNA amplicon sequencing (V3-V4 region) using the Illumina's MiSeq platform in order to better understanding the modulation of the microbiota by the supplementation of $U$. ohnoi in fish diet. Differences in the microbiota composition between the anterior and posterior sections and the effect of the presence of Ulva in the diet are described in the present study.

\section{MATERIALS AND METHODS}

\section{Diet Composition and Preparation}

Ulva ohnoi Hiraoka and Shimada strain UOHN120810 was isolated from the outlet channel of fish cultivation facilities in IFAPA El Toruño (El Puerto de Santa María, Cádiz, Spain) and maintained in culture. To obtain the biomass needed for the trial, stock cultures were up-scaled to $1000 \mathrm{~L}$ tanks. Ulva biomass $\left(1 \mathrm{~kg} \mathrm{~m}^{-3}\right)$ was cultured for 2 weeks under natural photoperiod light using a modified f/2 medium (Guillard, 1975) with $1.8 \mathrm{mM}$ nitrate and $0.1 \mathrm{mM}$ phosphate prepared with filtered $(0.2 \mu \mathrm{m})$ natural seawater. Algae were harvested, rinsed with tap water, freeze-dried and kept in a dry place until used as ingredient in the experimental diet.

\section{Experimental Diets}

Two isonitrogenous (55\% on dry weight basis) and isolipidic (15\% on dry weight) experimental diets were manufactured at the CEIA3-Universidad de Almería facilities (Service of Experimental Diets $)^{1}$. Ulva diet was formulated to include 5\% (w/w) dry $U$. ohnoi biomass. An algae-free diet was used as control. The ingredient composition of experimental diets is shown in Table 1.

Feed ingredients were finely ground and mixed in a vertical helix ribbon mixer (Sammic BM-10, 10-L capacity, Sammic, Azpeitia, Spain) before fish oil and diluted choline chloride were added. All the ingredients were mixed together for $15 \mathrm{~min}$, and then water $\left(300 \mathrm{~mL} \mathrm{~kg}^{-1}\right)$ was added to the mixture to

\footnotetext{
${ }^{1}$ http://www.ual.es/stecnicos_spe
} 
TABLE 1 | Ingredient composition of the experimental diets used in the feeding trial.

\begin{tabular}{|c|c|c|}
\hline & Control diet & Ulva diet \\
\hline \multicolumn{3}{|l|}{ Ingredients (g kg $\left.{ }^{-1} \mathrm{DM}\right)$} \\
\hline Fishmeal $\mathrm{LT}^{-1}$ & 674 & 660 \\
\hline Ulva meal & & 50 \\
\hline Squid meal ${ }^{2}$ & 50 & 50 \\
\hline Fish protein hydrolysate 3 & 50 & 50 \\
\hline Krill meal $^{2}$ & 10 & 10 \\
\hline Shrimp meal ${ }^{2}$ & 10 & 10 \\
\hline Gluten meal $^{2}$ & 20 & 20 \\
\hline Soybean protein concentrate ${ }^{4}$ & 20 & 20 \\
\hline Fish oil & 29 & 28 \\
\hline Soybean lecithin & 20 & 20 \\
\hline Maltodextrin & 46 & 11 \\
\hline Choline chloride $^{5}$ & 10 & 10 \\
\hline Vitamin and mineral premix ${ }^{6}$ & 20 & 30 \\
\hline Guan gum² & 15 & 15 \\
\hline Alginate $^{2}$ & 15 & 15 \\
\hline
\end{tabular}

${ }^{1}$ (69.4\% crude protein, $12.3 \%$ crude lipid), Norsildmel (Bergen, Norway); ${ }^{2}$ Local provider (Lifebioencapsulation SL, Almería, Spain); ${ }^{3}(81 \%$ crude protein, $8.8 \%$ crude lipid) Sopropeche (France); ${ }^{4}(65 \%$ crude protein, $8 \%$ crude lipid) DSM (France); ${ }^{5}$ Sigma-Aldrich (Madrid, Spain); ${ }^{6}$ Mineral and vitamin premix according to Vizcaíno et al. (2018). Proximate composition of control diet: $55.2 \%$ crude protein, $12.4 \%$ crude lipid, $3.0 \%$ fiber, $12.8 \%$ ash), and Ulva diet: $55.0 \%$ crude protein, $12.0 \%$ crude lipid, 3.3\% fiber, $13.1 \%$ ash.

obtain homogeneous dough. The dough was passed through a single screw laboratory extruder (Miltenz 51SP, JSConwell Ltd., New Zealand), to form 1-2 $\mathrm{mm}$ (diameter) and 2-3 mm (length) pellets. The extruder barrel consisted of four sections and the temperature profile in each section (from inlet to outlet) was 100C, 95, 90, and $85^{\circ} \mathrm{C}$, respectively. Finally, pellets were dried at room temperature for $24 \mathrm{~h}$ and kept in sealed plastic bags at $-20^{\circ} \mathrm{C}$ until use.

\section{Fish Maintenance and Sampling Procedures}

Juvenile Senegalese sole (Solea senegalensis) with mean initial body weight of $10.7 \pm 2.9 \mathrm{~g}$ were obtained from a commercial hatchery (Cupimar S.A., San Fernando, Cádiz, Spain) and transported to the research facilities of the IFAPA El Toruño (El Puerto de Santa María, Cádiz, Spain). Fish were stocked at $1.5 \mathrm{~kg} \mathrm{~m}^{-2}$ in six tanks connected to a closed recirculation consisting of a mechanical filter, a skimmer, ultraviolet light and a biofilter. Fish were fed daily at $2 \%$ fish biomass with an experimental diet considered as control diet for 10 days for acclimatizing the fish to the experimental conditions. After the acclimation period, fish (12.3 $\pm 2.0 \mathrm{~g}$ mean body weight) of each set of three tanks were fed with two different experimental diets: control diet (control diet) and diet containing U. ohnoi $5 \%$ (Ulva diet) for 45 days at a rate of $3 \%$ of their body weight. Different parameters were registered during all the experimental period. The temperature, $\mathrm{pH}$, salinity and oxygen were maintained constant at $19.9 \pm 0.7^{\circ} \mathrm{C}, 7.8 \pm 0.2 ; 25.7 \pm 1.5 \%$ and $7.0 \pm 0.4 \mathrm{mg} \mathrm{L}^{-1}$ respectively. Nitrite and ammonia were checked once a week (values were always below $0.1 \mathrm{mg} \mathrm{L}^{-1}$ ).
At the end of the feeding trial (45 days), fish were fasted for $24 \mathrm{~h}$ for sampling. Soles $(N=6)$ were carefully taken from their respective tanks and transferred to a new tank containing clove oil $(200 \mathrm{ppm})$ to euthanize. Whole intestines of six fish per treatment ( 2 per tank) were aseptically removed, divided into two equal length sections and stored separately in Trisure, $-80^{\circ} \mathrm{C}$, until further analysis.

\section{DNA Extraction, PCR Amplification and Sequencing}

Individual intestinal content was collected with $1 \mathrm{~mL}$ PBS $\mathrm{pH}$ 7.2 , and $1 \mathrm{~mL}$ aliquot per sample was centrifuged $(1000 \times g$, $5 \mathrm{~min})$. Total DNA was extracted from each sample $(N=12)$ according to manufacturer specifications using Trisure (Bioline, Spain) and purified by sodium acetate precipitation $(20 \mu \mathrm{l}$ DNA was precipitated with $2 \mu \mathrm{l}$ sodium acetate $3 \mathrm{M}$ and $46 \mu \mathrm{l}$ isopropanol). Then, DNA was centrifuged for $3 \mathrm{~min}$ at $12,000 \times \mathrm{g}, 4^{\circ} \mathrm{C}$. Supernatants were discarded and the pellets rinsed with cold $70 \%$ ethanol and centrifuged for 5-15 min at $12,000 \times g, 4^{\circ} \mathrm{C}$. Supernatants were discarded again and pellets air dried. Finally, DNA was resuspended in water. DNA quality and integrity was visualized by electrophoresis in 1\% agarose gels, stained with GelRed Nucleic Acid Stain 20000x (InTRON Biotechnology, Seoul, Korea). Concentration and purity were determined by using Qubit 2.0 fluorometer (Thermo Fisher Scientific, Germany). DNA was stored at $-20^{\circ} \mathrm{C}$ for further processing and $30 \mathrm{ng}$ were used for subsequent analyses.

Libraries were constructed by Chunlab, Inc., (Seoul, South Korea) using the Illumina MiSeq Platform. Briefly, Illumina paired-end sequencing of each sample was carried out by using the primers 341F CCTACGGGNGGCWGCAG and 805R GACTACHVGGGTATCTAATCC (ChunLab), targeting $\mathrm{V} 3-\mathrm{V} 4$ regions of $16 \mathrm{~S}$ rRNA gene.

After removing Illumina barcodes and demultiplexing, pairedend reads were merged by using PANDAseq software (Masella et al., 2012) and processed for primer sequence trimming according to BIOiPLUG in-house pipeline. Then, the assembled reads were quality-filtered one sample at a time using BIOiPLUG pipeline, excluding reads $<80$ bp or $>2,000$ bp long, with Phred quality score average below 25. Non-specific PCR amplicons not predicted as a $16 \mathrm{~S}$ gene by the Hidden Markov Model (HMM) based search were also removed. Singleton sequences were excluded in the subsequent analyses. Following, denoising was performed with DUDE.Seq software and sequences were de-replicated.

UCHIME (Edgar et al., 2011) was used to detect and remove chimera against BIOiPLUG's chimera-free reference database. The remaining representative, non-chimeric sequences were then subjected to taxonomic assignment against the EzBioCloud 16S database (Yoon et al., 2017), with 97\% 16S similarity as the cutoff and clustered into operational taxonomic units (OTUs) using UCLUST open reference method (Rideout et al., 2014).

After generating the taxonomic profile of microbiome samples, comparison of taxa present in the samples was carried out. Random subsampling was conducted to normalize the data size to 15,000 reads, because the total number of reads 
that remained after pre-processing varied depending on the samples and this size was below the minimum number of reads obtained in all the samples. All statistical analyses were performed using this subset. To determine the level of sequencing depth, rarefaction curves were obtained by plotting the number of observed OTUs against the number of sequences and Good's coverage coefficient calculated. Alpha diversity was estimated based in Shannon-Wiener, Chaol and Simpson indexes, in order to assay taxonomic and phylogenetic structure diversity, respectively. The results are generally presented at phylum and genus taxonomic level.

\section{Calculations and Statistical Analysis}

Growth parameters and survival rate were calculated according to the following expressions:

Weight gain rate $(\mathrm{WGR})(\%)=100 \times($ final body weight initial body weight)/initial body weight; Feed conversion ratio $($ FCR $)=$ Dry feed consumed $(\mathrm{g}) /$ wet weight gain $(\mathrm{g})$ and Survival rate $(\%)=100 \times$ final fish number/initial fish number.

Good's coverage, rarefaction curves and alpha diversity indices including $\mathrm{CHAO} 1$ richness estimation and community diversity (Shannon index and Simpson) were calculated according to Caporaso et al. (2011) using ChunLab platform.

Normality (Shapiro-Wilk) and homogeneity of variance (Levene test) were checked and statistical significance of growth data and alpha diversity values was determined by One-Way Analysis of Variance (ANOVA) followed by Tukey test to determine significance of paired comparisons. All tests were performed with XLSTAT software.

Multivariate analysis of OTU data was performed via Principal Coordinate Analysis (PCoA) of OTU profiles using Bray Curtis metric in order to depict differences between microbiota of each group. In addition, to test the hypothesis of no differences between the microbiota of the GI sections and diets assayed, dissimilarity matrices obtained with Bray-Curtis index were analyzed by Permutation multivariate analysis of variance (PERMANOVA) with 999 permutations by using PAST software (Hammer, 2001) version 3.16. Linear discriminant analysis (LDA) effect size (LEfSe) (Segata et al., 2011) was used to characterize microbial differences of biological relevance between the diets within the two different GI sections and between sections within the same diet. The LEfSe analysis was performed using an alpha value of 0.05 for both the factorial Kruskal-Wallis rank sum test and pairwise Wilcoxon test and a threshold of 2.0 for the LDA. BIOiPLUG was used to carry out LefSe analysis.

\section{Ethics Statement}

All studies involving fish were conducted in strict accordance with Guidelines established by the European Union (2010/63/UE) and the Spanish legislation (RD 1201/2005 and RD $53 / 2013$ ) for the use of laboratory animals. All procedures were authorized by the Bioethics and Animal Welfare Committee of the Institute of Agricultural and Fisheries Research and Training (IFAPA), and given the registration number 17/11/2016/171 according to the national authorities for regulation of animal care and experimentation.

\section{RESULTS}

\section{Fish Growth, Sequencing Overview and Microbiota Characterization}

No fish mortality occurred during the experimental period; however, slightly decreased final body weight and weight gain rate values were obtained for fish fed with $U$. ohnoi supplemented diet (Table 2).

DNA was extracted from 24 samples, six S. senegalensis specimens per diet and 2 intestinal regions per fish specimen. In total, 653,198 raw reads were obtained for both forward and reverse directions after sequencing. The mean read depth per sample was 27,216.58 \pm 7,578 (mean \pm SD) sequences per read direction. After removing non-specific amplicons, amplicons not assigned to the target taxon, and chimeras in the initial quality filtering, 613,800 sequences passed with a mean of $25,575.00 \pm 6,677.07$ (mean \pm SD) sequences per sample. Singletons were removed and a total of 3638 OTUs at a $97 \%$ gene similarity cut off against EzBioCloud database were used for subsequent analysis. Random subsampling was conducted to normalize the data size to 15,000 reads.

\section{Alpha Diversity}

Alpha diversity indices were calculated for microbiota data of both control and Ulva diets (Table 3).

Mean Good's coverage estimator value was $99.7 \pm 0.1$ (mean \pm SD) (ranging from 99.7 to $99.8 \%$ ), indicating adequate sequencing depth. No significant differences in species richness were observed in the microbiota of the samples studied. Thus, no statistically significant differences in OTU number or Chaol richness estimates were detected between control and Ulva diet microbiota neither in anterior or posterior GI sections. However, both Shannon and Simpson indices showed statistically significant differences in the anterior portion of the GI tract based on the diet received by the fish $(p=0.028$ and $p=0.027$,

TABLE 2 | Growth performance and survival of juvenile Solea senegalensis specimens fed control (Control) and U/va ohnoi (5\%) supplemented (Ulva) diets for 45 days.

\begin{tabular}{|c|c|c|c|c|}
\hline & FBW(g) & WGR (\%) & FCR & Survival (\%) \\
\hline Control diet & $28.22 \pm 6.12^{\mathrm{a}}$ & $129.6 \pm 40.8^{a}$ & $0.85 \pm 0.02^{a}$ & 100 \\
\hline Ulva diet & $24.88 \pm 4.18^{b}$ & $101.7 \pm 38.9^{b}$ & $1.06 \pm 0.01^{b}$ & 100 \\
\hline
\end{tabular}

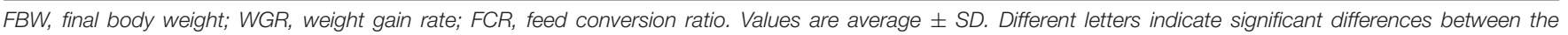
experimental diets $(p<0.05)$. 
respectively), higher diversity being observed in fish fed Ulva diet. On the contrary, no significant changes in Shannon and Simpson indices were detected between the microbiota of control and alga supplemented groups in the posterior GI sections $(p>0.05)$.

When anterior and posterior sections of the GI tract were compared, higher Shannon diversity and lower Simpson index values were detected in the microbiota of the posterior GI region of fish receiving the diet devoid of Ulva ( $p=0.004$ and $p=0.001$, respectively), with no significant differences in diversity in the case of fish fed Ulva supplemented diet $(p>0.05)$.

\section{S. senegalensis GI Microbiota Composition}

Phyla detected with average values above $1 \%$ in samples from fish fed with control and Ulva supplemented diets included Proteobacteria, Spirochaetes, and Tenericutes in both GI sections, whilst Bacteroidetes was only detected in the posterior sections of fish fed with Ulva diet (Figure 1). Proteobacteria was the dominant phylum in all the cases, higher percentages being found in the microbiota of the anterior GI region of fish fed with control and Ulva supplemented diets (92.62 and $83.32 \%$, respectively) compared to the posterior regions (66.11 and $56.17 \%$, respectively). Interestingly, GI microbiota of fish fed with Ulva diet contained lower Proteobacteria levels compared

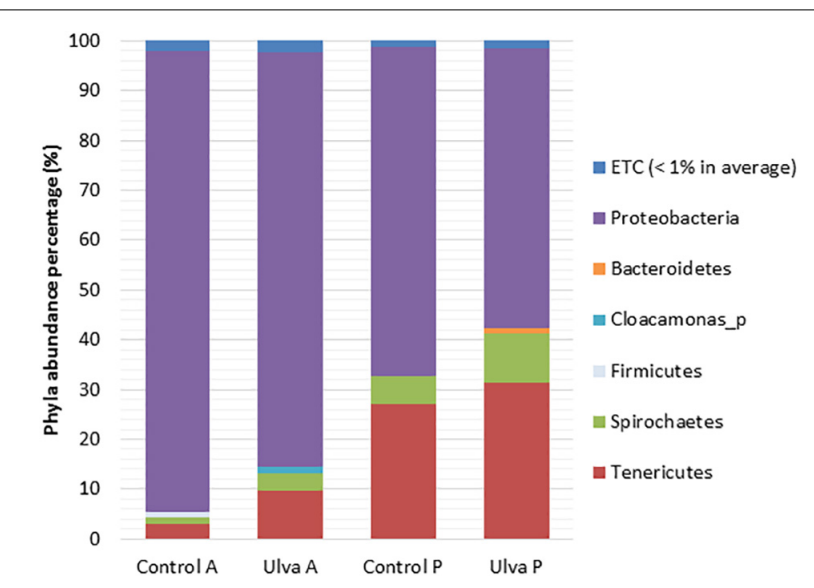

FIGURE 1 | Gut microbiota composition (relative OTU composition) at phylum level of the gastrointestinal tract of $S$. senegalensis specimens fed control (Control) and U/va ohnoi supplemented (U/va) diet for 45 days. A, anterior half region; P, posterior half region. to the fish fed control diet. High variability in relative abundance values was observed in the microbiota of fish fed with Ulva diet, especially in the anterior sections. Nevertheless, it was possible to observe overrepresentation of Tenericutes members in the posterior GI sections, especially in fish fed Ulva diet. Other phyla such as Actinobacteria and Firmicutes were detected with average values below $1 \%$ in the microbiota of all samples analyzed, although Firmicutes abundance reached average values above 1\% $(1.06 \%)$ only in the anterior GI sections of control fish. Finally, Cloacamonas_p was detected in the microbiota of the anterior sections in Ulva fed fish (1.15\%).

When composition of the microbiota was considered at genus level, Pseudomonas was the most abundant taxon in the anterior GI region regardless of the diet received by $S$. senegalensis specimens ( 80.87 and $66.74 \%$ in control and Ulva group, respectively) (Figure 2). These percentages decreased in the posterior sections, the lowest percentages corresponding to fish fed with Ulva diet $(39.21 \%$,). On the contrary, abundance percentages of Mycoplasmataceae_f1_uc and Brevinema increased in the posterior regions, this latter especially in Ulva diet fed specimens. Members of Vibrio genus were detected in the microbiota of all GI regions regardless of the diet. However, they were overrepresented in the anterior region

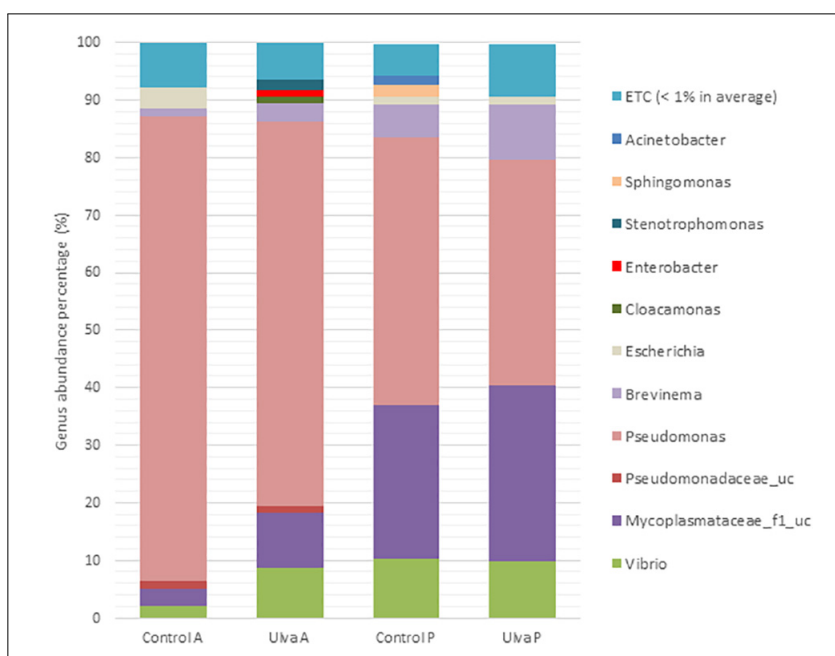

FIGURE 2 | Gut microbiota composition (relative OTU composition) at genus level of the gastrointestinal tract of $S$. senegalensis specimens fed control (Control) and Ulva ohnoi (U/va) supplemented diets for 45 days. A, anterior half region; P, posterior half region.

TABLE 3 | Alpha diversity of bacterial communities in the anterior (A) and posterior (P) intestinal tract regions of juvenile Solea senegalensis specimens fed control (Control) and U/va ohnoi (5\%) supplemented (UIva) diets for 45 days.

\begin{tabular}{lccccc}
\hline Diet & OTU & Chao1 & Shannon & Simpson & Good's coverage (\%) \\
\hline Control A & $205.67 \pm 48.42$ & $230.53 \pm 58.50$ & $1.01 \pm 0.15^{*} \neq$ & $0.69 \pm 0.07^{*} \neq$ & $99.7 \pm 0.1$ \\
Ulva A & $201.50 \pm 47.48$ & $229.40 \pm 41.30$ & $1.60 \pm 0.54^{*}$ & $0.48 \pm 0.19^{*}$ & $99.7 \pm 0.1$ \\
Control P & $213.33 \pm 53.63$ & $227.42 \pm 62.71$ & $1.72 \pm 0.40 \neq$ & $0.39 \pm 0.147$ & $99.7 \pm 0.2$ \\
Ulva P & $271.33 \pm 88.41$ & $280.67 \pm 81.98$ & $2.23 \pm 0.62$ & $0.30 \pm 0.14$ & $99.8 \pm 0.1$
\end{tabular}

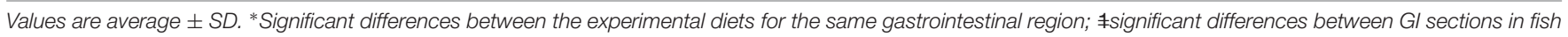
fed the same diet, $p<0.05$. 
of fish fed Ulva diet (8.67\%) compared to those fed control diet (2.03\%) (Figure 2).

\section{Beta Diversity}

To study community structure, principal coordinate analysis based on Bray Curtis metric was carried out by using BIOiPLUG comparative MTP analyser. The significance of differences in microbiota composition between samples from fish receiving each diet was tested with permutational multivariate analysis of variance (PERMANOVA) based on Bray-Curtis index. Fish separated in two groups according to the OTUs detected in their anterior GI sections depending on the diet received (Figure 3A) and PERMANOVA analysis revealed an effect of Ulva supplementation on the microbiota of the anterior GI tract $(p=0.005)$. However, no separation between fish receiving control and Ulva supplemented diet was observed when microbiota of the posterior GI sections was considered $(p=0.576)$ (Figure 3B). Finally, microbiota composition of the anterior and posterior regions was compared for each diet group. In this case, the analysis showed separation of samples based on the GI section in fish fed control diet $(p=0.005)$ but not in the case of those receiving Ulva diet ( $p=0.105$ ) (Figures $4 \mathbf{A}, \mathbf{B}$ ).

In order to determine the OTUs most likely to explain differences between GI sections and diets analyzed, LDA effect size (LEFSe) method according to Segata et al. (2011) was performed. Thus, OTUs differentially abundant between diet groups were detected and effect size values allowed to provide an estimation of the magnitude of the differences between groups due to each OTU detected.

Histograms of the LDA scores computed for differentially abundant OTUs in the GI microbiota of $S$. senegalensis specimens fed with control and Ulva diets and anterior and posterior GI sections are shown in Figures 5-8. LEfSe scores can be interpreted as the degree of consistent difference in relative abundance between features in the two classes of analyzed microbial communities. The histogram identifies the clades that explain the greatest differences between communities. In the case of the anterior GI sections of fish fed with control and Ulva diet, the most differentially abundant bacterial taxa $(p<0.01)$ in the microbiota of Ulva diet fed specimens belong to Gammaproteobacteria. Several members of Vibrionaceae family showed high LDA scores, Vibrio genus being the most differentially abundant, with higher abundance percentages in fish receiving dietary U. ohnoi (Figure 5). In addition, Achromobacter (Betaproteobacteria), Luteibacter, Nevskia and Shewanella (Gammaproteobacteria) as well as Crocinitomicaceae_uc and Paludibacter (Bacteroidetes), Brucella (Alphaproteobacteria) and Alcaligenaceae_uc (Betaproteobacteria) were more abundant in the microbiota of fish fed with the alga.

On the contrary, a wider variety of more differentially abundant taxa was detected in the microbiota of fish fed with control diet. In this case, the most differentially abundant genus was Escherichia. Other Gammaproteobacteria including Colwellia, Neptunibacter, Cosaenzaea, and Haemophilus were also more abundant in the microbiota of fish belonging to the control group. Interestingly, Tenacibaculum genus, which includes pathogenic species for $S$. senegalensis, was more abundant in the microbiota of fish fed with the diet devoid of U. ohnoi. In addition, Actinomyces (Actinobacteria), Saprospiraceae_uc (Bacteroidetes) and two members of Firmicutes phylum: Bacillus and Clostridium_g21 were more abundant in the microbiota of control fish.

Differential taxa at genus level in the microbiota of posterior sections of control and Ulva supplemented diets fed fish was only represented by Lacinutrix (Bacteroidetes) and four Proteobacteria genera: Nevskia, more abundant in the microbiota of Ulva diet group, and Sphingomonas, Massilia and Moraxellaceae_uc, more abundant in the microbiota of control fish (Figure 6). These results are in agreement with the lack of statistically significant differences detected in the previous PERMANOVA analysis of the composition of the microbiota of posterior GI sections.

When the microbiota of anterior and posterior GI sections of fish fed with control diet was compared, highest LDA scores corresponded to Gammaproteobacteria. These taxa were more abundant in anterior sections, a value of 5.24 corresponding to Pseudomonas genus (Figure 7), $80.87 \%$ relative abundance (Figure 2). Other Gammaproteobacteria such as Enterobacter, Stenotrophomonas, and Cosenzaea were also more abundant in the anterior GI sections. Firmicutes phylum was also overrepresented in the anterior sections compared to posterior sections. Thus, OTUs identified as Staphylococcus, Bacillus, Selenomonadaceae_uc and Pseudoflavonifractor, although with low relative percentages, are more abundant in anterior sections. On the contrary, microbiota of posterior sections of control fish was characterized by higher abundance of members of Tenericutes phylum such as Mycoplasmataceae_f1 and Mycoplasma_g12.

Finally, when microbiota of anterior and posterior GI sections of Ulva diet fed specimens were compared, only 8 genera showed LDA scores above 2.00 (Figure 8). However, similar to fish fed control diet, members of Tenericutes were differentially more abundant in the microbiota of posterior sections of fish belonging to the Ulva group (Figure 1), though in this case OTUs were identified as Mycoplasmatales_uc (LDA score $3.128, p<0.05)$. At genus level, differentially abundant taxa were all overrepresented in anterior sections of $S$. senegalensis GI tract. These taxa consisted of Enterobacter, Achromobacter, Sphingomonas, Acidovorax, Moraxellaceae_uc and Caulobacter (Proteobacteria) as well as Propionibacterium (Actinobacteria) and Bacteroides (Bacteroidetes). These data were expected considering the overlapped distribution of samples observed in principal coordinates analysis plots and the lack of differences in the PERMANOVA analysis of microbiota composition (Figures 3, 4).

Despite limitations in some closely related species due to the lack of sequence differences, EzBioCloud 16S database can be used for species-level identification in some genera (Kim et al., 2012; Yoon et al., 2017). For this reason, presence of OTUs identified as potential pathogens for S. senegalensis including groups such as Tenacibaculum spp., $P$. damselae group (including $P$. damselae subsp. piscicida), V. alginolyticus group (including $V$. harveyi) and $V$. parahaemolyticus group (including 


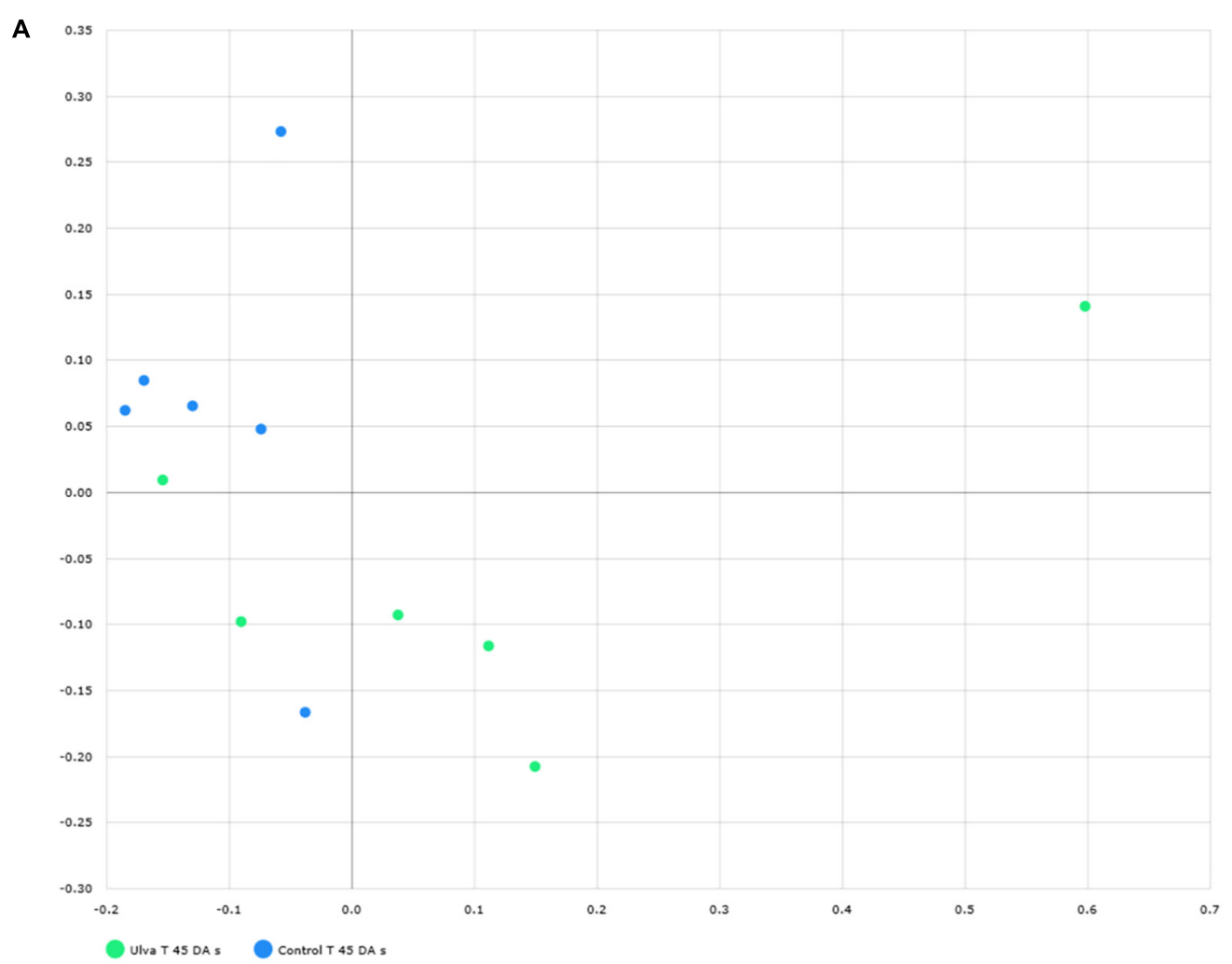

.

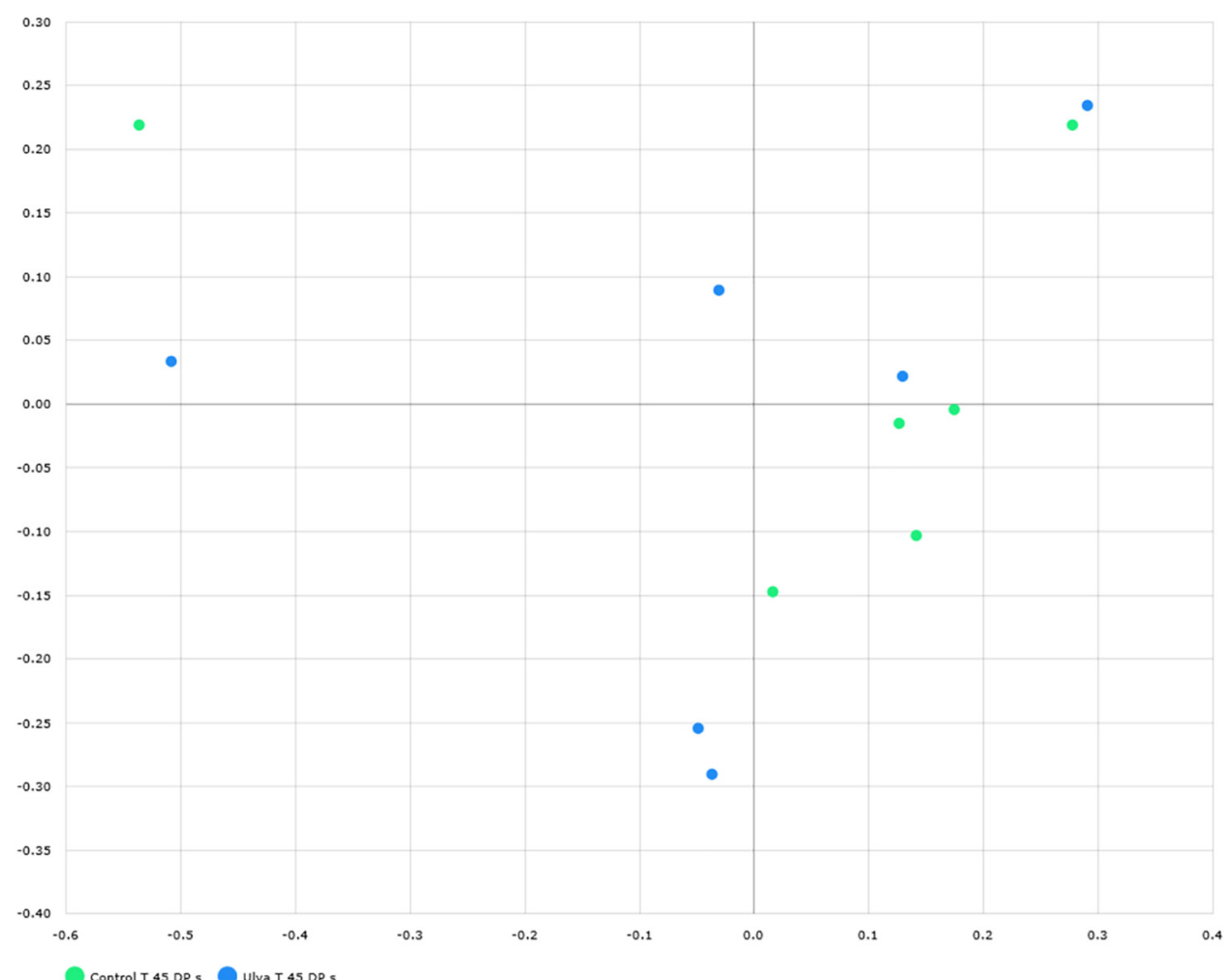

FIGURE 3 | Distribution of GI microbiome samples of S. senegalensis specimens fed control and U. ohnoi (5\%) supplemented diet for 45 days. Principal coordinates analysis was applied based on Bray Curtis index. Microbiota of anterior (A) and posterior (B) sections in control (green) and U/va (blue) diet groups. (B) Microbiota of posterior sections in control (green) and Ulva (blue) diet groups. 
A

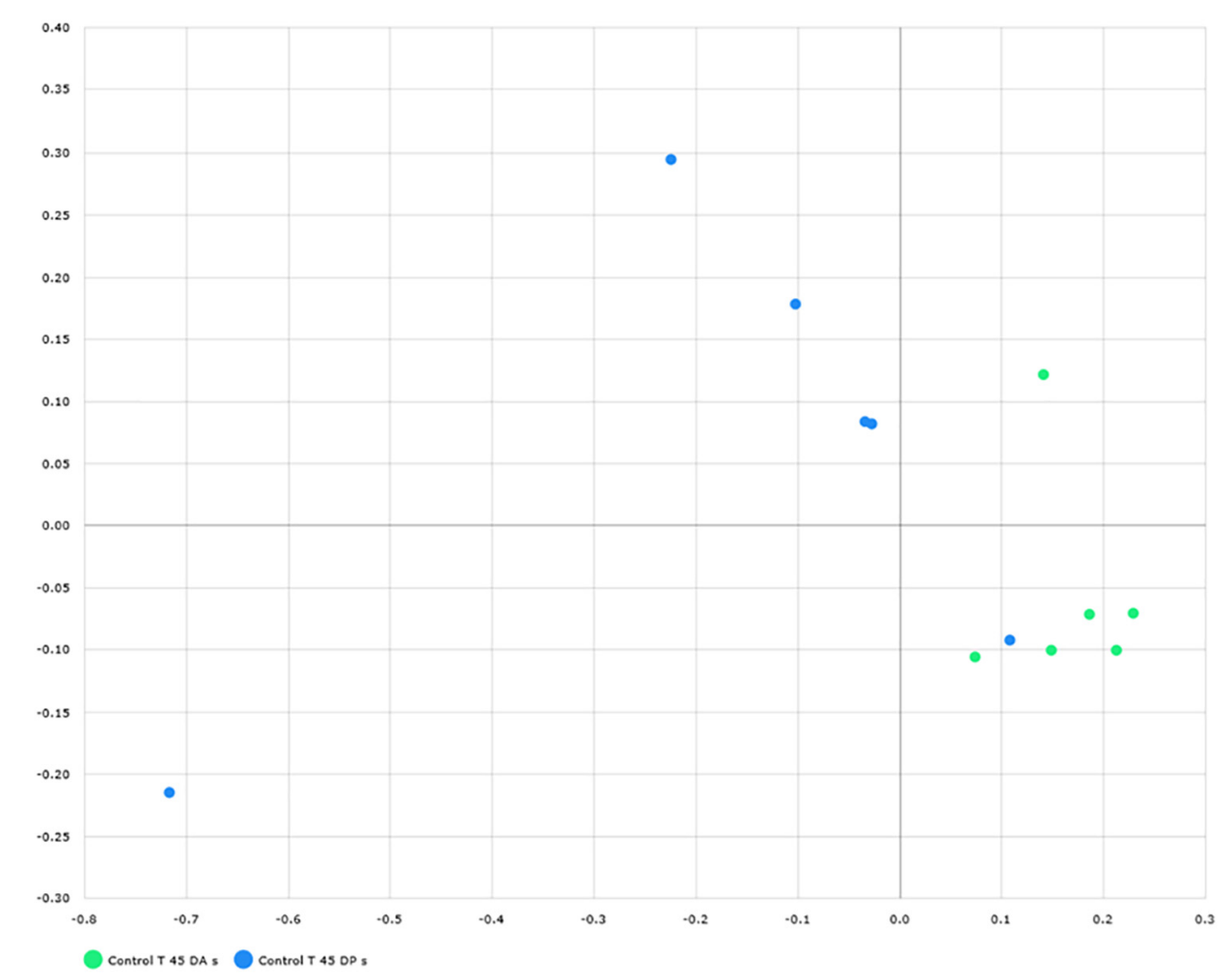

B

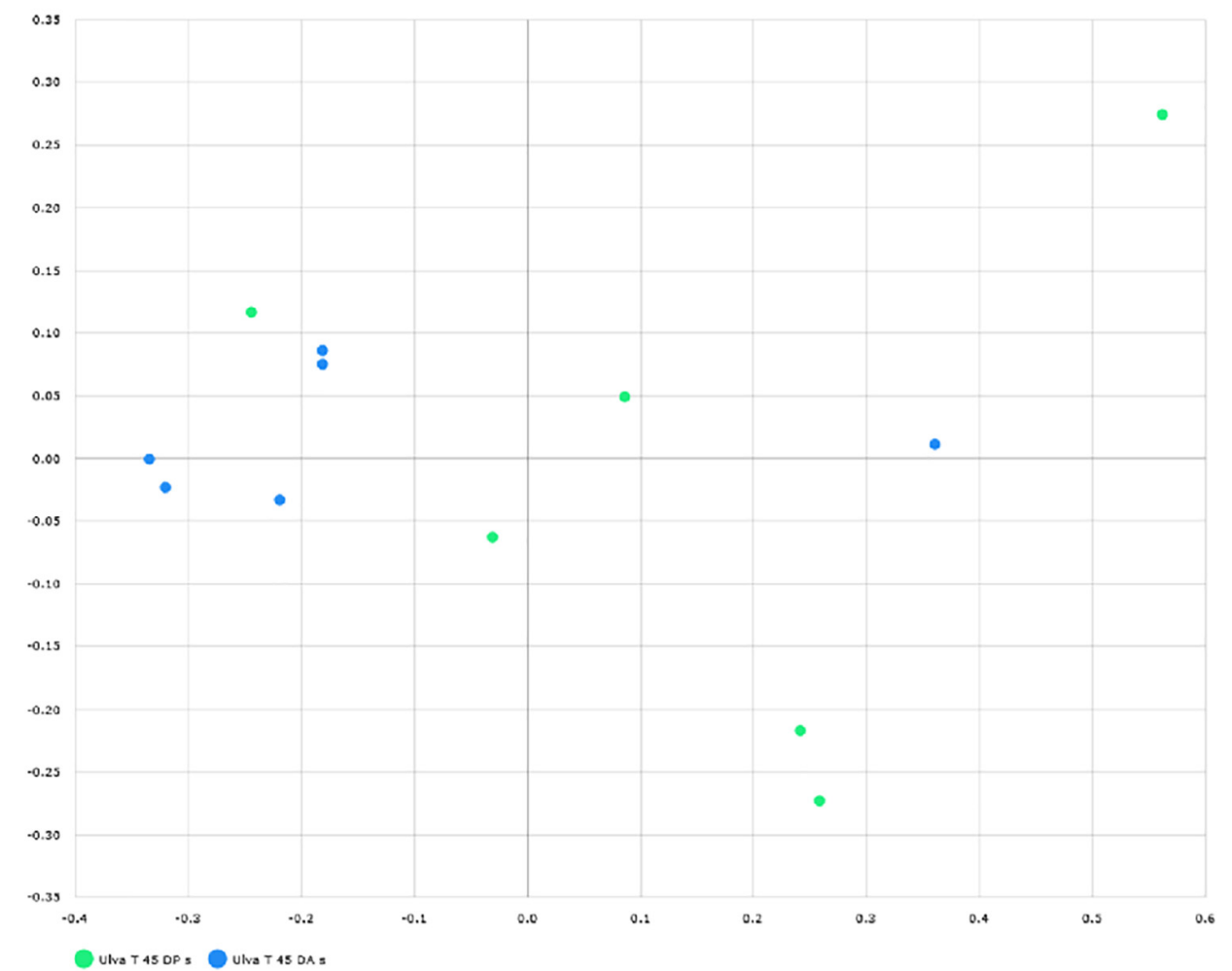

FIGURE 4 | Distribution of GI microbiome samples of S. senegalensis specimens fed control and U. ohnoi (5\%) supplemented diet for 45 days. Principal coordinates analysis was applied based on Bray Curtis index. Microbiota in anterior (blue) and posterior (green) sections offish fed with control diet (A) and U/va diet (B). 


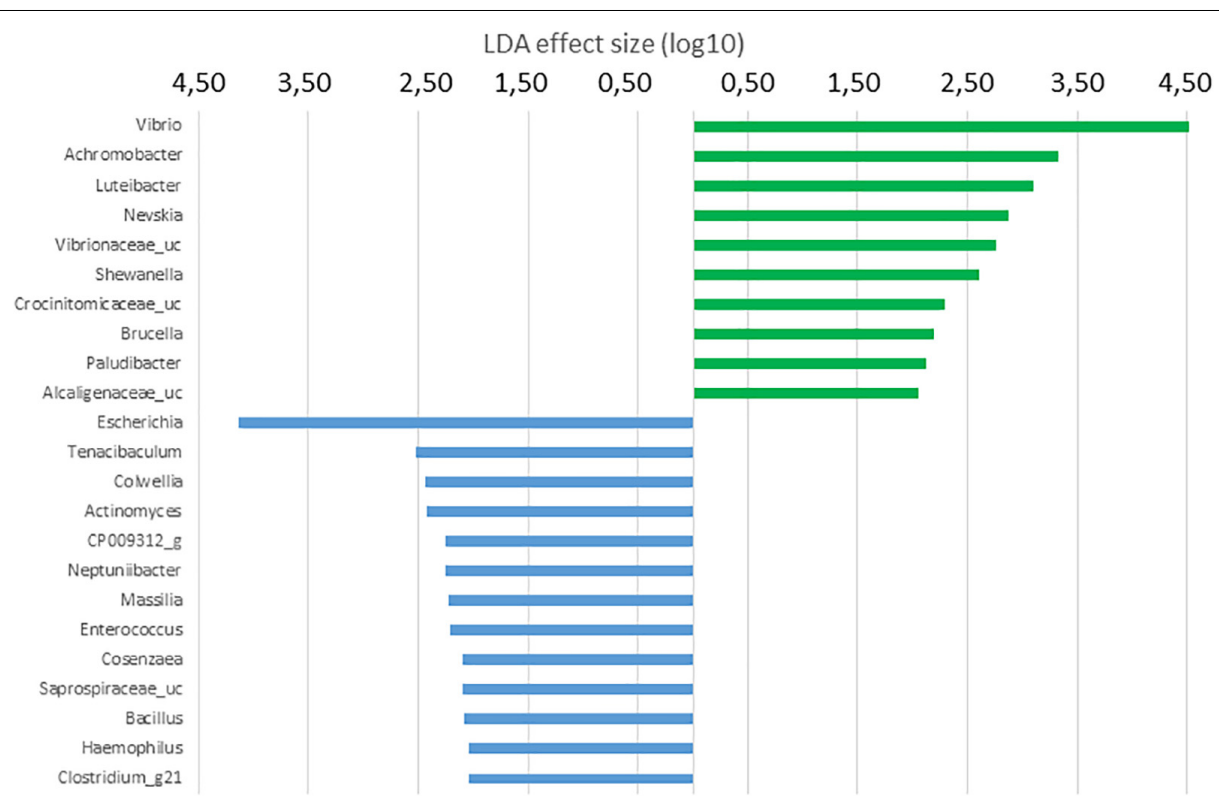

FIGURE 5 | LDA scores for OTUs at genus level differentially abundant in the microbiota of the anterior GI tract of $S$. senegalensis specimens fed control (blue) and U/va supplemented (5\%w/w) (green) diets, $p<0.05$.

$V$. parahaemolyticus) were searched for in the samples analyzed. Presence in the microbiota of anterior and posterior GI sections of specimens fed with each diet assayed is shown in Figure 9. Similar detection percentages of $P$. damselae, $V$. alginolyticus and $V$. parahaemolyticus groups were observed in the microbiota of Senegalese sole specimens fed with both diets. Although no OTU was identified as $V$. harveyi in the samples studied, presence of members included in $V$. alginolyticus group were detected in samples from fish fed with both control and Ulva diet. However, it was not possible to determine whether these OTUs correspond to $V$. harveyi or other species included in $V$. alginolyticus group according to EzBiocloud database.

On the contrary, OTUs identified as Tenacibaculum were detected in a lower number of specimens fed with Ulva diet (1 out of 6 specimens) compared to control diet (4 out of 6 specimens) and only in the posterior GI section (Figure 9). OTUs belonging to Tenacibaculum genus detected in samples from fish fed with control diet were identified as T. soleae (1 specimen), T. litoreum group including T. discolor, T. gallaicum, T. litoreum and T. ascidiaceicola (1 specimen), T. halocynthiae (3 specimens) and T. lutimaris group, including T. aestuarii and T. lutimaris (3 specimens). OTUs detected in the only positive sample from fish fed with $U$. ohnoi were assigned to T. lutimaris group.

\section{DISCUSSION}

\section{Characterization of Solea senegalensis GI Microbiota}

A number of studies indicate that diet nature is an important factor in the modulation of the GI tract microbial composition

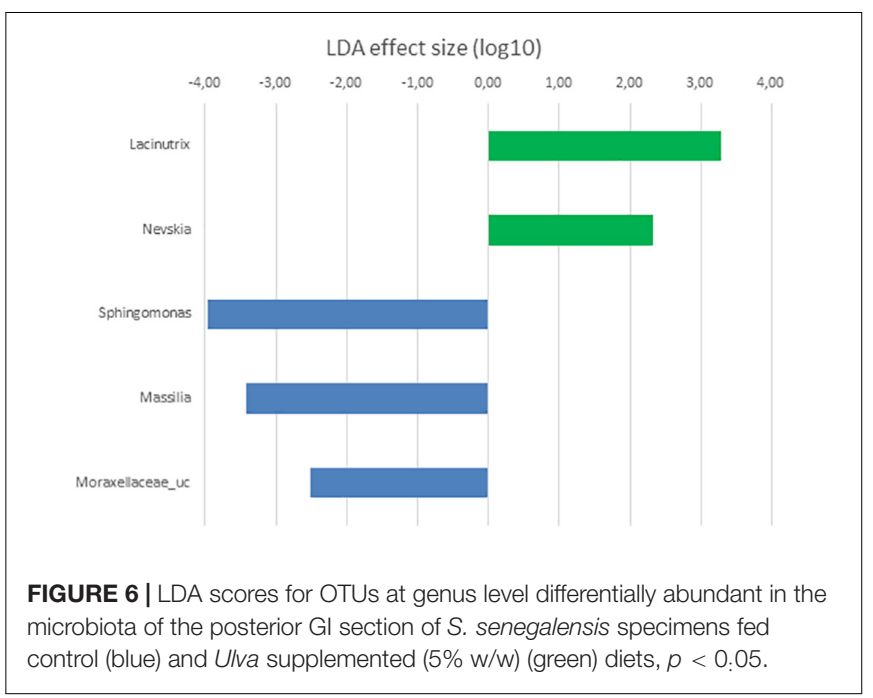

in vertebrates (Askarian et al., 2012; Sullam et al., 2012; Ghanbari et al., 2015; Ringø et al., 2016; Gajardo et al., 2017).

In the present work, NGS techniques (MiSeq) have been used to study $S$. senegalensis GI microbiota for the first time. Overall composition detected in S. senegalensis GI microbiota reflects that described for other marine fish species (VernerJeffreys et al., 2003; Xing et al., 2013; Egerton et al., 2018; Wang et al., 2018). In the case of S. senegalensis, previous studies have reported $\gamma$-Proteobacteria as main components of GI microbiota by using DGGE (Tapia-Paniagua et al., 2010, 2014b). At genus level, Pseudomonas and Vibrio were detected in the microbiota of juvenile $S$. senegalensis specimens (Tapia-Paniagua et al., 2015). Results obtained with NGS techniques in the present 


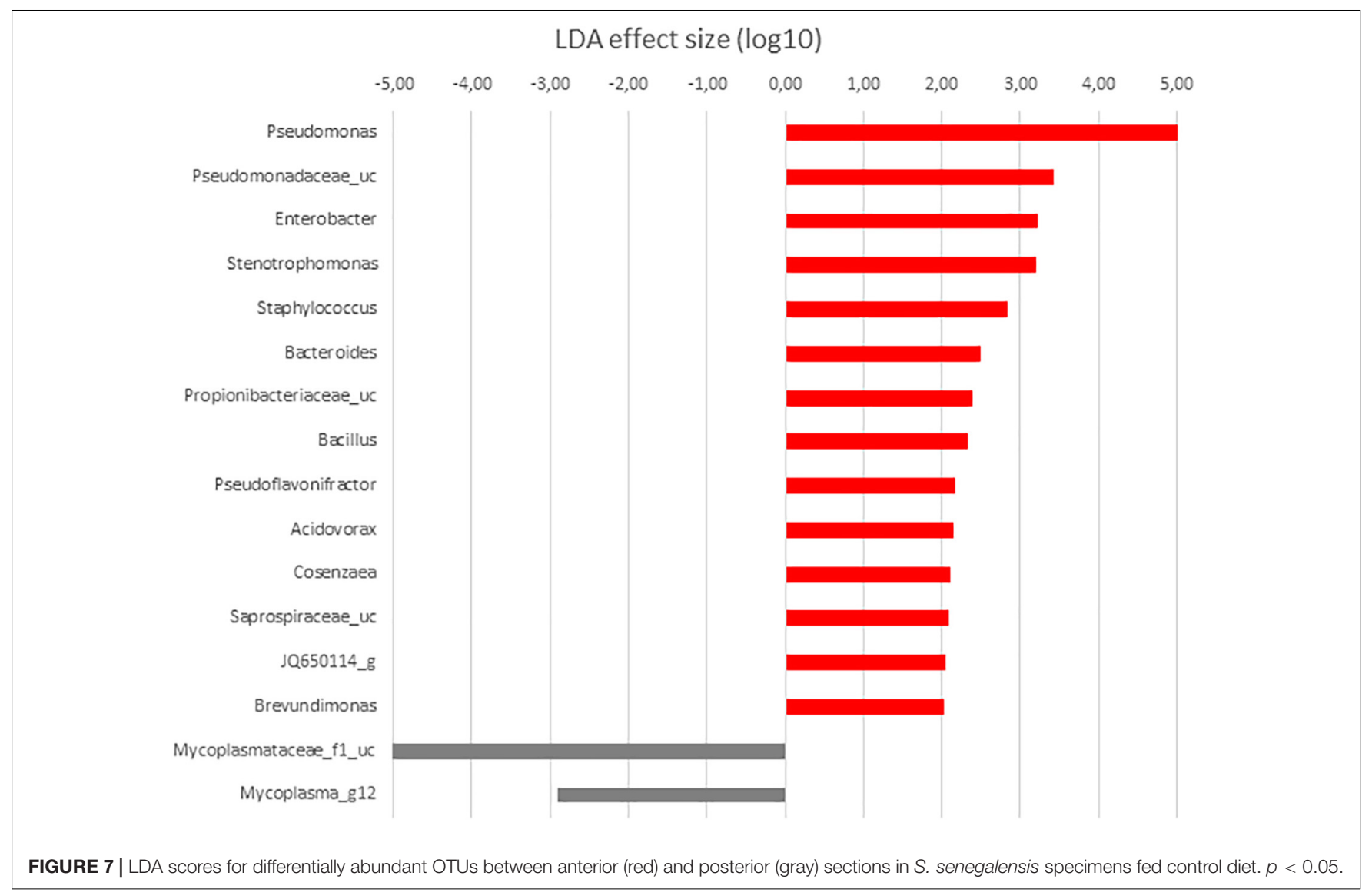

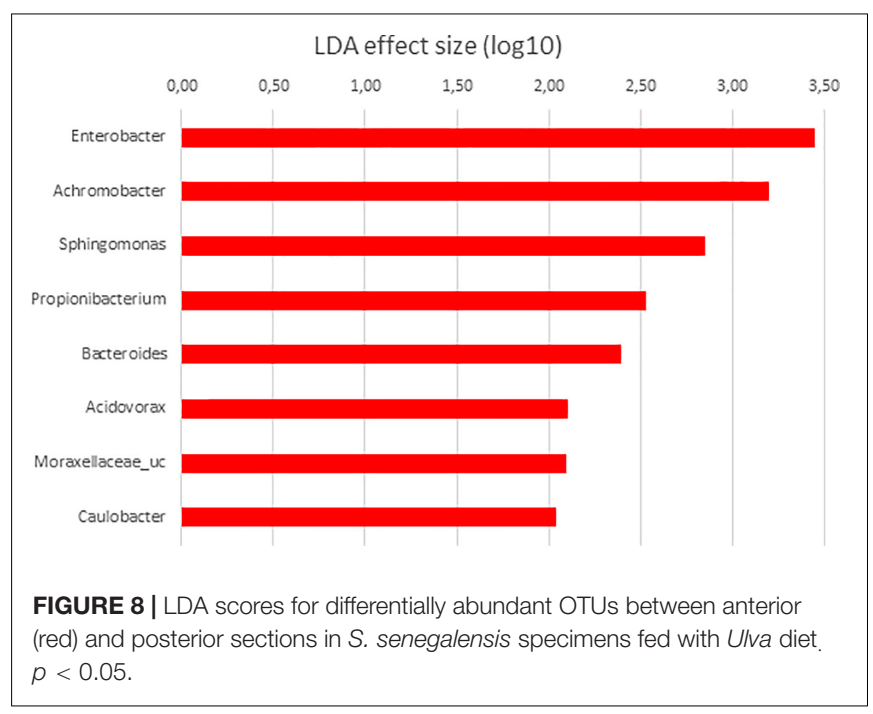

work confirm that members of Proteobacteria phylum dominate the microbiota of the GI tract in S. senegalensis specimens. Similarly, at genus level, Pseudomonas was the most frequently Proteobacteria detected in the present work, especially in anterior sections, although Vibrio, Acinetobacter, and Escherichia were also present.

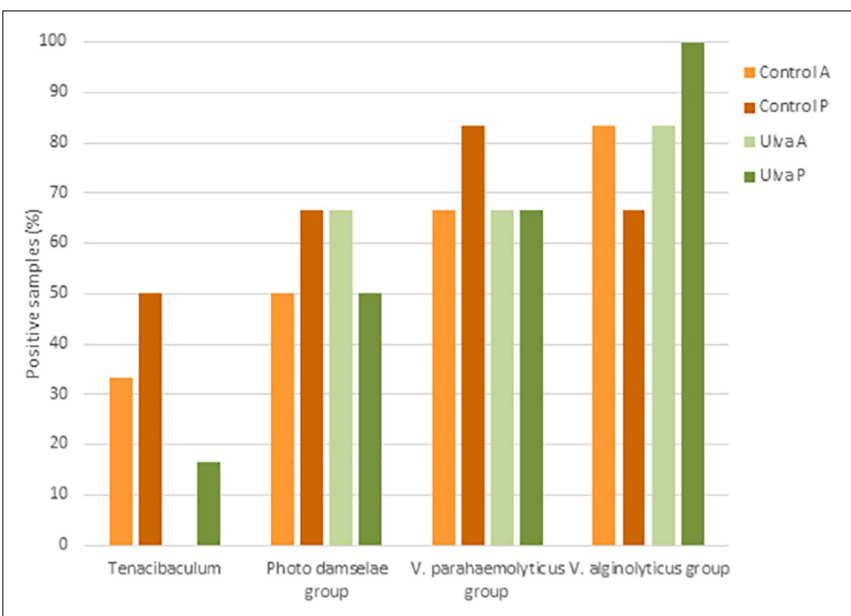

FIGURE 9 | Presence of potential pathogenic taxa in the intestinal microbiota of $S$. senegalensis specimens fed with control or Ulva supplemented diet $(5 \%$ $\mathrm{W} / \mathrm{W})$. Values represent percentages of positive samples for $N=6$ specimens per gastrointestinal section and diet group. A: anterior Gl tract sections; P: posterior Gl tract sections.

Pseudomonas species are commonly detected in aquaculture and intestinal environments, it being one of the dominant members of the GI microbiota in marine fish (Wang et al., 2018). In this respect, studies carried out by 
Tapia-Paniagua et al. (2014a) have detected Pseudomonas as a predominant genus in the GI microbiota of $S$. senegalensis larvae (Tapia-Paniagua et al., 2014a), though not in juvenile specimens (Tapia-Paniagua et al., 2014b, 2015). Differences in rearing conditions such as the temperature, with increased abundance of Pseudomonas members when water temperature is higher $\left(19^{\circ} \mathrm{C}\right.$ in the present study, versus $\left.16.6^{\circ} \mathrm{C}\right)$ and diet (manufactured diet containing krill and shrimp meal in the present study versus commercial diet), could contribute to differential abundance of Pseudomonas in the GI microbiota of Senegalese sole specimens. Nonetheless, this genus was predominant in the intestinal microbiota of juvenile Senegalese sole fed a diet supplemented with a probiotic Shewanella strain (Tapia-Paniagua et al., 2015). Changes in the abundance of Pseudomonas could be relevant considering that this genus includes species with chitinase, lipase, protease and amylase activities (Ray et al., 2012). Further studies need to be carried out to detect these activities in the species contained in $S$. senegalensis GI tract and verify their role in the digestive process of this fish species.

In this study, Vibrio genus was the second most abundant $\gamma$-Proteobacteria in S. senegalensis GI tract of both fish groups. Vibrio has already been reported as a predominant member of the GI microbiota of larvae (Tapia-Paniagua et al., 2015) and juvenile (Tapia-Paniagua et al., 2014a,b, 2015) S. senegalensis specimens. In our study, Vibrio sequences were mainly assigned to $V$. scophthalmi. This species has been described as the dominant bacterial population in the intestine of healthy reared flat fish such as turbot (Scophthalmus maximus) (Cerdá-Cuéllar and Blanch, 2002) and S. senegalensis (Tapia-Paniagua et al., 2014b, 2015). In addition, $V$. scophthalmi has been identified as a chitinase-producing bacteria from the digestive tract of Japanese flounder (Paralichthys olivaceus) (Sugita and Ito, 2006). However, whether populations of $V$. scophthalmi would allow $S$. senegalensis to use the nutrients derived from chitin needs to be determined. In addition, $V$. harveyi and $V$. parahaemolyticus have been detected as a predominant microorganism in the GI microbiota of S. senegalensis specimens farmed under high stocking rearing conditions (Tapia-Paniagua et al., 2014b). Some strains of both species have been reported as opportunistic pathogens for S. senegalensis (Zorrilla et al., 2003; Tapia-Paniagua et al., 2015) whereas others were non virulent for this fish (Rico et al., 2008).

Tenericutes was the second most abundant phylum in S. senegalensis GI tract. This phylum has previously been detected in the GI tract of both marine and freshwater fish species (Xing et al., 2013; Carda-Dieguez et al., 2014; Givens et al., 2015; Lyons et al., 2017). In the present work, relative abundance of members of this phylum, and its class Mollicutes, mainly phylotype Mycoplasmataceae, was differentially higher in the posterior sections of $S$. senegalensis GI tract, where abundance of Pseudomonas decreased. Mycoplasma has been reported as dominant components in the gut microbiota of carnivorous fish species (Bano et al., 2007; Green et al., 2013) and S. senegalensis (Tapia-Paniagua et al., 2014a,b). Composition of the diet used for feeding $S$. senegalensis specimens in the present work included ingredients from animal sources such as fish, squid, krill and shrimp meal, which can have favored Mycoplasmataceae populations.

Mycoplasma genus includes both pathogenic and saprophytic species. Glucose is the main source of energy for fermentative mycoplasma and a source of carbon for the synthesis of other sugar and carbohydrates. Additionally, acetic and lactic acids are produced by the bacterium (Brown, 2010). Mycoplasma species have optimal growth at $\mathrm{pH}$ values between 7 and 8 and $\mathrm{pH}$ deviations are usually inhibitory for most species (Kirchhoff et al., 1987). S. senegalensis GI tract is characterized by a low capacity for acid digestion, with most of the digestion occurring under alkaline conditions (Yúfera and Darias, 2007). This environment would be more favorable for the establishment of Mycoplasma populations, explaining the higher abundance of these taxa, especially in the posterior sections of S. senegalensis GI tract. As Lyons et al. (2017) suggest for rainbow trout, the dominance of Mycoplasma in the posterior sections of S. senegalensis GI tract may result from a symbiosis in which the bacterium benefits of the access to host fermentable substrates, and the fish obtains acetic and lactic acid metabolites. In this way, although more research to identify the definite role of Mycoplasma is needed, it is interesting to point out that Li et al. (2016) found higher Tenericutes percentages in healthy Coreius guichenoti specimens compared to those suffering from furunculosis.

Despite no important changes in $\mathrm{pH}$ values are present along S. senegalensis GI tract, the anterior and posterior regions differ in their physiological functions, with various sets of digestive enzymes that render different substrates available for microorganisms (Yúfera and Darias, 2007). This situation can explain changes in microbial populations between GI regions indicated above and differences in diversity observed between anterior and posterior sections analyzed in this work. Similar to that reported by Ye et al. (2014) in gizzard shad (Dorosoma cepedianum) and Gajardo et al. (2017) in Atlantic salmon, diversity of $S$. senegalensis microbiota was higher in the posterior GI regions. However, other authors have reported no differences between GI regions in Artic charr (Salvelinus alpinus) (Nyman et al., 2017) or higher diversity in the anterior locations of the mottled spinefoot rabbitfish (Siganus fuscescens) GI tract (Nielsen et al., 2017). These results may reflect the variety of GI tract environments present in fish species and point out to the interest in differentiating along GI locations. In the present work, variations in the microbiota composition along S. senegalensis GI microbiota have been described for the first time.

\section{Effect of Diet Supplementation With Low Percentage of Ulva ohnoi}

No differences were detected in the richness (Chaol index) but diversity (Shannon index) in the GI microbiota of S. senegalensis increased in fish fed with Ulva supplemented diet. These findings may indicate changes in relative abundance distribution of OTU among taxa, but not the presence of new taxa in the microbiota of specimens receiving dietary U. ohnoi. Similarly, Givens (2012) and Lyons et al. (2017) reported increased diversity in the microbiota of fish species such as Lagodon rhomboides and O. mykiss, respectively, fed with diets supplemented with algae. 
Microbial ecosystem function and stability are influenced by species and functional group richness (Bell et al., 2005), which along with the biodiversity, are essential in protecting ecosystem functionality against changes (De et al., 2014; Goncalves and Gallardo-Escárate, 2017).

In the present work, GI microbiota of $S$. senegalensis specimens fed with the diet containing $U$. ohnoi showed significantly increased abundance of Vibrio compared to the microbiota of fish fed the control diet. As no signs or symptoms of disease were observed in these fish during the experimental period, no relationship with disease can be established.

Lower growth and feed conversion rates observed in S. senegalensis receiving Ulva diet in the present study are in accordance with results in rainbow trout juveniles fed diets with $10 \%$ U. lactuca reported by Yildirim et al. (2009). The reduced growth observed in fish fed the Ulva-supplemented diet could be attributed to the presence of anti-nutritional factors that might be associated with the decreased growth performance. It has been demonstrated that Ulva-supplemented diets impaired protein digestibility in salmonids (Pereira et al., 2012; Norambuena et al., 2015 ) and induced lower protein retention in rainbow trout (Yildirim et al., 2009). Regarding these findings, Sáez et al. (2013) confirmed that $U$. rigida contains substances capable to inhibit the intestinal proteases of seabream juveniles. Indeed, Vizcaíno et al. (2015) reported that intestinal proteolytic activity was reduced after dietary administration of Ulva in juvenile seabream in a 70 day-feeding trial.

Thus, in Senegalese sole, the overall lower nutrient gain and growth impairment observed in fish fed U. ohnoi might be partially explained by the presence of protease inhibitors that could have adversely affected nutrient uptake through the inhibition of digestive proteases in the intestine. However, Vizcaíno et al. (2015) suggested the existence of a compensation mechanism in seabream owing to that profile of intestinal proteases in fish remains unaffected by dietary inclusion of Ulva meal, and no effects on final fish growth was observed. In this sense, microbiota could contribute with its enzymatic pool to compensate this limitation; nonetheless, the effects of $U$. ohnoi on microbial proteases need to be determined. Moreover, Moutinho et al. (2018) reported that dietary inclusion of $10 \%$ U. lactuca over 5 months (from $23 \mathrm{~g}$ up to $60 \mathrm{~g}$ ) did not have any detectable effect on growth performance and feed utilization in juvenile Senegalese sole. The different response of fish after dietary administration of Ulva might be consequence of the different physiological maturation level of specimens used in both feeding trials. Results obtained appointed that early dietary administration of Ulva resulted in growth impairment associated with reduced food conversion rate, and for this reason belated administration of Ulva could be recommended in the culture of Senegalese sole to avoid the observed effect in the growth when feeding small-size juvenile fish.

On the other hand, microbiota of Senegalese sole specimens fed with the control diet showed differentially higher abundance of OTUs identified as members of Escherichia genus. Several authors have reported antibacterial activity against E. coli strains in extracts of Ulva spp. (Chiheb et al., 2009; Silva et al., 2013). This characteristic could be associated to the lower abundance of this genus in the microbiota of $S$. senegalensis specimens receiving the Ulva diet compared to those fed with the control diet.

Presence of pathogens in recirculating aquaculture systems and GI tract of S. senegalensis and S. maximus specimens without disease symptoms has been previously observed (Martins et al., 2013; Tapia-Paniagua et al., 2014b). V. parahaemolyticus strains have been reported as pathogenic for $S$. senegalensis (Zorrilla et al., 2003) and other marine fish species (Abdelaziz et al., 2017). In the present study, sequences identified as $V$. parahaemolyticus and $V$. harveyi groups were detected in the microbiota of fish fed with both diets. Our results are in agreement with the proposal of Givens et al. (2015) who suggested that fish guts might serve as a refuge for $V$. parahaemolyticus. However, results obtained in the present work do not allow us to elucidate if sequences detected correspond to pathogenic species and a carrier status of this fish, or to non-virulent strains.

OTUs assigned to $P$. damselae group including $P$. damselae subsp. damselae and $P$. damselae subsp. piscicida were also detected in the microbiota of Senegalese sole specimens regardless of the diet received. Previous studies have reported the presence of $P$. damselae subsp. piscicida in S. senegalensis GI microbiota (Tapia-Paniagua et al., 2014a,b). Similarly, Rico et al. (2016) detected predominant bands related to Photobacterium OTUs in DGGE gels when analyzing the GI microbiota of Sparus aurata fed diets containing Ulva rigida (5\%, 15 and 25\%). TapiaPaniagua et al. (2014a,b) and Rico et al. (2016) suggested that the high abundance of naturally antagonistic species in the system may avoid the reach of infective concentrations and would contribute to the control of pathogen populations.

In contrast to previously mentioned pathogens, we have detected significantly lower presence of Tenacibaculum in the GI tract of S. senegalensis specimens fed with a diet containing U. ohnoi. Infections caused by Tenacibaculum, affect a wide range of marine species, including Atlantic salmon, flounder (Baxa et al., 1986), turbot (Alsina and Blanch, 1993) seabass (D. labrax), and S. senegalensis (Avendaño-Herrera et al., 2005). Although the best known and most extensively studied outbreaks are caused by T. maritimum, other Tenacibaculum spp. are responsible for fish disease (Småge et al., 2016a,b) and species such as T. discolor and T. soleae have been isolated from diseased Senegalese sole (Piñeiro-Vidal et al., 2008a,b; Morais et al., 2016). Presence of inhibitory compounds against some bacterial species has been reported in Ulva extracts (Silva et al., 2013; Reverter et al., 2014). However, this alga does not show high antibacterial activities in their extracts compared to other seaweed species, and inhibition on Tenacibaculum spp. has not been reported.

The contribution of the saprophytic microbiota in the control of pathogens has been reported (Kamada et al., 2013). In this study, differentially abundant genera in the GI microbiota of anterior and posterior intestine of $S$. senegalensis receiving Ulva diet included genera with strains displaying antagonistic activities such as Vibrio (LaPorte, 2017), Shewanella (Chabrillón et al., 2005) and Achromobacter (Deepa et al., 2015). These results could suggest an important role in the control of Tenacibaculum members by microbial populations comprising the microbiota in fish receiving dietary $U$. ohnoi. Furthermore, the detection of pathogenic species in Senegalese sole specimens jointly with the 
lack of signs of disease could indicate the presence of a carrier stage and the control of pathogen populations. In this way, the presence of $T$. maritimum in the intestinal tract of apparently healthy fish has been reported by some authors, suggesting that the intestine may act as a reservoir for this pathogen (Faílde et al., 2013). Results obtained in the present work indicate that a diet containing $U$. ohnoi $(5 \%)$ is associated to lower presence of Tenacibaculum in the GI tract, thus it being able to limit not only the risk of pathology in the fish but also the potential transmission of the pathogen to other hosts.

\section{CONCLUSION}

Differences in the microbiota composition of anterior and posterior sections of $S$. senegalensis GI tract have been observed, Pseudomonas being more abundant in the anterior sections and Mycoplasmataceae the dominant taxon in the posterior GI tract sections. On the other hand, modulation of the GI microbiota of juvenile Senegalese sole fed with a diet containing low percentage of $U$. ohnoi for 45 days has been detected in the present study.

\section{REFERENCES}

Abdelaziz, M., Ibrahem, M. D., Ibrahim, M. A., Nermeen, A. E., and AbdelMoneam, D. A. (2017). Monitoring of different vibrio species affecting marine fishes in lake qarun and gulf of suez: phenotypic and molecular characterization. Egypt. J. Aquatic. Res. 43, 141-146. doi: 10.1016/j.ejar.2017. 06.002

Aguilera, E., Yany, G., and Romero, J. (2013). Cultivable intestinal microbiota of yellowtail juveniles (Seriola lalandi) in an aquaculture system. Lat. Am. J. Aquat. Res. 41, 395-403.

Alsina, M., and Blanch, R. (1993). First isolation of Flexibacter maritimus from cultivated turbot. Bull. Eur. Ass. Fish Pathol. 13, $157-160$.

Askarian, F., Zhou, Z., Olsen, R. E., Sperstad, S., and Ringø, E. (2012). Culturable autochthonous gut bacteria in Atlantic salmon (Salmo salar L.) fed diets with or without chitin. Characterization by $16 \mathrm{~S}$ rRNA gene sequencing, ability to produce enzymes and in vitro growth inhibition of four fish pathogens. Aquaculture 326-329, 1-8. doi: 10.1016/j.aquaculture.2011. 10.016

Avendaño-Herrera, R., Magariños, B., Moriñigo, M. A., Romalde, J. L., and Toranzo, A. E. (2005). A novel O-serotype in Tenacibaculum maritimum strains isolated from cultured sole (Solea senegalensis). Bull. Eur. Ass. Fish Pathol. 25, 70-74.

Bano, N., DeRae Smith, A., Bennett, W., Vasquez, L., and Hollibaugh, J. T. (2007). Dominance of Mycoplasma in the guts of the long jawed mudsucker, Gillichthys mirabilis, from five California salt marshes. Environ. Microbiol. 9, 2636-2641. doi: 10.1111/j.1462-2920.2007.01381.x

Bates, J. M., Mittge, E., Kuhlman, J., Baden, K. N., Cheesman, S. E., and Guillemin, K. (2006). Distinct signals from the microbiota promote different aspects of zebrafish gut differentiation. Dev. Biol. 297, 374-386. doi: 10.1016/j. ydbio.2006.05.006

Baxa, D. V., Kawai, K., and Kusuda, R. (1986). Characteristics of gliding bacteria isolated from diseased cultured flounder, Paralichthys olivaceus. Fish Pathol. 21, 251-258. doi: 10.3147/jsfp.21.251

Bell, T., Newman, J. A., Silverman, B. W., Turner, S. L., and Lilley, A. K. (2005). The contribution of species richness and composition to bacterial services. Nature 436, 1157-1160. doi: 10.1038/nature03891

Brown, D. R. (2010). "Bergey's Manual of Systematic Bacteriology" in The Bacteroidetes, Spirochaetes, Tenericutes (Mollicutes), Acidobacteria, Fibrobacteres, Fusobacteria, Dictyoglomi, Gemmatimonadetes, Lentisphaerae, Verrucomicrobia, Chlamydiae, and Planctomycetes, Vol. 4, eds, N. R. Krieg,
Microbiota of anterior regions of GI tract has been mainly been modulated and a significant reduction in the presence of Tenacibaculum has been observed in fish specimens receiving dietary U. ohnoi.

\section{AUTHOR CONTRIBUTIONS}

ST-P and MF performed the sampling, DNA extraction, and data collection. CF-D and VA participated in sampling, cultivation of the algae, and fish maintenance. FA prepared the aquafeed. $\mathrm{MM}$ and $\mathrm{MB}$ performed the data analysis and wrote the manuscript. MB, MM, CF-D, and FA designed the work. All authors contributed to the discussion and final writing.

\section{FUNDING}

This work was supported by INIA, Ministerio de Economía y Competitividad and co-financed by FEDER funds (Grant No. RTA2014-00023 C02).

W. Ludwig, W. B. Whitman, B. P. Hedlund, B. J. Paster, J. T. Staley, et al. (New York, NY: Springer), 567-723.

Caporaso, J. G., Lauber, C. L., Walters, W. A., Berg-Lyons, D., Lozupone, C. A., Turnbaugh, P. J., et al. (2011). Global patterns of 16S rRNA diversity at a depth of millions of sequences per sample. Proc. Natl. Acad. Sci. U.S.A. 15(108 Suppl. 1), 4516-4522. doi: 10.1073/pnas.1000080107

Carda-Dieguez, M., Mira, A., and Fouz, B. (2014). Pyrosequencing survey of intestinal microbiota diversity in cultured sea bass (Dicentrarchus labrax) fed functional diets. FEMS Microbiol. Ecol. 87, 451-459. doi: 10.1111/1574-6941. 12236

Cerdá-Cuéllar, M., and Blanch, A. R. (2002). Detection and identification of Vibrio scophthalmi in the intestinal microbiota of fish and evaluation of host specificity. J. Appl. Microbiol. 93, 261-268. doi: 10.1046/j.1365-2672.2002.01 697.x

Chabrillón, M., Rico, R. M., Arijo, S., Díaz-Rosales, P., Balebona, M. C., and Moriñigo, M. A. (2005). Interactions of microorganisms isolated from gilthead sea bream, Sparus aurata L., on Vibrio harveyi, a pathogen of farmed Senegalese sole, Solea senegalensis (Kaup). J. Fish Dis. 28, 531-537. doi: 10.1111/j.13652761.2005.00657.x

Cheesman, S. E., Neal, J. T., Mittge, E., Seredick, B. M., and Guillemin, K. (2011). Epithelial cell proliferation in the developing zebrafish intestine is regulated by the Wnt pathway and microbial signalling via Myd88. Proc. Natl. Acad. Sci. U.S.A. 108, 4570-4577. doi: 10.1073/pnas.100007 2107

Chiheb, I., Riadi, H., Martinez-Lopez, J., Dominguez Seglar, J. F., Gomez Vidal, J. A., Bouziane, H., et al. (2009). Screening of antibacterial activity in marine green and brown macroalgae from the coast of Morocco. Afr. J. Biotechnol. 8, 1258-1262.

De, C. B., Meena, D. K., Behera, B. K., Das, P., Das Mohapatra, P. K., and Sharma, A. P. (2014). Probiotics in fish and shellfish culture: immunomodulatory and ecophysiological responses. Fish Physiol. Biochem. 40, 921-971. doi: 10.1007/ s10695-013-9897-0

Deepa, I., Kumar, S. N., Sreerag, R. S., Nath, V. S., and Mohandas, C. (2015). Purification and synergistic antibacterial activity of arginine derived cyclic dipeptides, from Achromobacter sp. associated with a rhabditid entomopathogenic nematode against major clinically relevant biofilm forming wound bacteria. Front. Microbiol. 6:876. doi: 10.3389/fmicb.2015.00876

Edgar, R. C., Haas, B. J., Clemente, J. C., Quince, C., and Knight, R. (2011). UCHIME improves sensitivity and speed of chimera detection. Bioinformatics 27, 2194-2200. doi: 10.1093/bioinformatics/bt r381 
Egerton, S., Culloty, S., Whooley, J., Stanton, C., and Paul Ross, R. (2018). The gut microbiota of marine fish. Front. Microbiol. 9:873. doi: 10.3389/fmicb.2018. 00873

Eichmiller, J., Hamilton, M. J., Staley, C., Sadowsky, M. J., and Sorensen, P. W. (2016). Environment shapes the fecal microbiome of invasive carp species. Microbiome 4:44. doi: 10.1186/s40168-016-0190-1

Ergün, S., Soyutürk, M., Güroy, B., Güroy, D., and Merrifield, D. (2008). Influence of Ulva meal on growth, feed utilization, and body composition of juvenile Nile tilapia (Oreochromis niloticus) at two levels of dietary lipid. Aquacult. Int. 17, 355-361. doi: 10.1007/s10499-008-9207-5

Faílde, L. D., Bermudez, R., Losada, A. P., Riaza, A., Santos, Y., and Quiroga, M. I. (2013). Immunohistochemical diagnosis of tenacibaculosis in paraffinembedded tissues of Senegalese sole Solea senegalensis Kaup, 1858. J. Fish Dis. 37, 959-968. doi: 10.1111/jfd.12199

Gajardo, K., Jaramillo-Torres, A., Kortner, T. M., Merrifield, D. L., Tinsley, J., Bakke, A. M., et al. (2017). Alternative protein sources in the diet modulate microbiota and functionality in the distal intestine of atlantic salmon (Salmo salar). Appl. Environ. Microbiol. 83:e2615-16. doi: 10.1128/AEM.026 15-16

Garcia-Casal, M. N., Pereira, A. C., Leets, I., Ramirez, J., and Quiroga, M. E. (2007). High iron content and bioavailability in humans from four species of marine algae. J. Nutr. 137, 2691-2695. doi: 10.1093/jn/137.12. 2691

Gatesoupe, F. J., Zambonino Infante, J. L., Cahu, C., and Quazuquel, P. (1997). Early weaning of seabass larvae, Dicentrarchus labrax: the effect on microbiota, with particular attention to iron supply and exoenzymes. Aquaculture 158, 118-127. doi: 10.1016/S0044-8486(97)00179-8

Ghanbari, M., Kneifel, W., and Domig, K. J. (2015). A new view of the fish gut microbiome: advances from next-generation sequencing. Aquaculture 448, 464-475.

Givens, C. E. (2012). A Fish Tale: Comparison of the Gut Microbiome of 15 Fish Species and the Influence of Diet and Temperature on its Composition. Georgia: Depart Marine Sciences, University of Georgia. doi: 10.1016/j.aquaculture.2015. 06.033

Givens, C. E., Ransom, B., Bano, N., and Hollibaug, J. T. (2015). Comparison of the gut microbiomes of 12 bony fish and 3 shark species. Inter. Res. MEPS 518, 209-223. doi: 10.3354/meps11034

Goncalves, A. T., and Gallardo-Escárate, C. (2017). Microbiome dynamic modulation through functional diets based on pre- and probiotics (mannanoligosaccharides and Saccharomyces cerevisiae) in juvenile rainbow trout (Oncorhynchus mykiss). J. Appl. Microbiol. 122, 1333-1347. doi: 10.1111/jam. 13437

Green, T. J., Smullen, R., and Barnes, A. C. (2013). Dietary soybean protein concentrate-induced intestinal disorder in marine farmed Atlantic salmon, Salmo salar is associated with alterations in gut microbiota. Vet. Microbiol. 166, 286-292. doi: 10.1016/j.vetmic.2013.05.009

Guillard, R. R. L. (1975). "Culture of phytoplankton for feeding marine invertebrates," in Culture of Marine Invertebrate Animals, eds W. L. Smith and M. H. Chanley (New York, NY: Plenum Press), 26-60.

Hammer, $\varnothing$. (2001). PAST: paleontological statistics software package for education and data analysis. Palaeontol. Electronica 4, 1-9.

Ingerslev, H. C., Jørgensen, L. V., Strube, M., Larsen, N., Dalsgaard, I., Boye, M., et al. (2014a). The development of the gut microbiota in rainbow trout (Oncorhynchus mykiss) is affected by first feeding and diet type. Aquaculture 424-425, 24-34. doi: 10.1016/j.aquaculture.2013.12.032

Ingerslev, H. C., Strube, M. L., Jørgensen, L. V., Dalsgaard, I., Boye, M., and Madsen, L. (2014b). Diet type dictates the gut microbiota and the immune response against Yersinia ruckeri in rainbow trout (Oncorhynchus mykiss). Fish Shellfish Immunol. 40, 624-633. doi: 10.1016/j.fsi.2014.08.021

Kamada, N., Chen, G. Y., Inohara, N., and Nuñez, G. (2013). Control of pathogens and pathobionts by the gut microbiota. Nat. Immunol. 14, 685-690. doi: $10.1038 /$ ni.2608

Kelly, C., and Salinas, I. (2017). Under pressure: interactions between commensal microbiota and the teleost immune system. Front. Immunol. 8:559. doi: 10.3389/fimmu.2017.00559

Kim, O. S., Cho, Y. J., Lee, K., Yoon, S. H., Kim, M., Na, H., et al. (2012). Introducing EzTaxon-e: a prokaryotic 16S rRNA gene sequence database with phylotypes that represent uncultured species. Int. J. Syst. Evol. Microbiol. 62, 716-721. doi: 10.1099/ijs.0.038075-0

Kirchhoff, H., Beyene, P., Fischer, M., Flossdorf, J., Heitmann, J., Khattab, B., et al. (1987). Mycoplasma mobile sp. nov., a new species from fish. Int. J. Syst. Bacteriol. 37, 192-197. doi: 10.1099/00207713-373-192

LaPorte, J. (2017). Biocontrol of Acute Hepatopacongreatic Necrosis Disease (AHPND). Open Access Master's Theses, Paper 1134. Available at: https://digitalcommons.uri.edu/theses/1134

Li, T., Long, M., Ji, C., Shen, Z., Gatesoupe, F. J., Zhang, X., et al. (2016). Alterations of the gut microbiome of largemouth bronze gudgeon (Coreius guichenoti) suffering from furunculosis. Sci. Rep. 6:30606. doi: 10.1038/srep3 0606

Llewellyn, M., Boutin, S., Hoseinifar, S. H., and Derome, N. (2014). Teleost microbiomes: progress towards their characterization, manipulation and applications in aquaculture and fisheries. Front. Microbiol. 5:207. doi: 10.3389/ fmicb.2014.00207

Lyons, P. P., Turnbull, J. F., Dawson, K. A., and Crumlish, M. (2017). Phylogenetic and functional characterization of the distal intestinal microbiome of rainbow trout Oncorhynchus mykiss from both farm and aquarium settings. J. Appl. Microbiol. 122, 347-363. doi: 10.1111/jam.13347

Martin-Antonio, B., Manchado, M., Infante, C., Zerolo, R., Labella, A., Alonso, C., et al. (2007). Intestinal microbiota variation in Senegalese sole (Solea senegalensis) under different feeding regimes. Aquacult. Res. 38, 1213-1222. doi: 10.1111/j.1365-2109.2007.01790.x

Martins, P., Cleary, D. F. R., Pires, A. C. C., Rodrigues, A. M., Quintino, V., Calado, R., et al. (2013). Molecular analysis of bacterial communities and detection of potential pathogens in a recirculating aquaculture system for Scophthalmus maximus and Solea senegalensis. PLoS One 8:e80847. doi: 10.1371/journal.pone.0080847

Masella, A. P., Bartram, A. K., Truszkowski, J. M., Brown, D. G., and Neufeld, J. D. (2012). PANDAseq: paired-eND assembler for illumina sequences. BMC Bioinformatics 13:31. doi: 10.1186/1471-2105-13-31

Merrifield, D. L., Dimitroglou, A., Foey, A., Davies, S. J., Baker, R. T. M., Bøgwald, J., et al. (2010). The current status and future focus of probiotic and prebiotic applications for salmonids. Aquaculture 302, 1-18. doi: 10.1016/j. aquaculture.2010.02.007

Morais, S., Aragao, C., Cabrita, E., Conceicao, L. E. C., Constenla, M., Costas, B., et al. (2016). New developments and biological insights into the farming of Solea senegalensis reinforcing its aquaculture potential. Rev. Aquacult. 8, 227-263. doi: 10.1111/raq.12091

Moroney, N. C., Wan, A. H. L., Soler-Vila, A., O'Grady, M. N., FitzGerald, R. D., Johnson, M. P., et al. (2017). Influence of green seaweed (Ulva rigida) supplementation on the quality and shelf life of Atlantic salmon fillets. J. Aquat. Food Prod. Technol. 26, 1175-1188. doi: 10.1080/10498850.2015.104 6099

Moutinho, S., Linares, F., Rodríguez, J. L., Sousa, V., and Valente, L. M. P. (2018). Inclusion of $10 \%$ seaweed meal in diets for juvenile and on-growing life stages of Senegalese sole (Solea senegalensis). J. Appl. Phycol. 30, 3589-3601. doi: 10.1007/s10811-018-1482-6

Mustafa, M. G., and Nakagawa, H. (1995). A review: dietary benefits of algae as an additive in fish feed. Isr. J. Aquac. Bamid. 47, 155-162.

Navarrete, P., Espejo, R. T., and Romero, J. (2009). Molecular analysis of microbiota along the digestive tract of juvenile Atlantic salmon (Salmo salar L.). Microb. Ecol. 57, 550-561. doi: 10.1007/s00248-0089448-x

Nielsen, S., Wilkes Walburn, J., Vergés, A., Thomas, T., and Egan, S. (2017). Microbiome patterns across the gastrointestinal tract of the rabbitfish Siganus fuscescens. PeerJ 5:e3317. doi: 10.7717/peerj. 3317

Norambuena, F., Hermon, K., Skrzypczyk, V., Emery, J. A., Sharon, Y., Beard, A., et al. (2015). Algae in fish feed: performances and fatty acid metabolism in juvenile atlantic salmon. PLoS One 10:e0124042. doi: 10.1371/journal.pone. 0124042

Nyman, A., Huyben, D., Lundh, T., and Dicksved, J. (2017). Effects of microbe- and mussel-based diets on the gut microbiota in Arctic charr (Salvelinus alpinus). Aquacult. Rep. 5, 34-40. doi: 10.1016/j.aqrep.2016. 12.003 
Ortiz, J., Romero, N., Robert, P., Araya, J., Lopez-Hernández, J., Bozzo, C., et al. (2006). Dietary fiber, amino acid, fatty acid and tocopherol contents of the edible seaweeds Ulva lactuca and Durvillaea antarctica. Food Chem. 99, 98-104. doi: 10.1016/j.foodchem.2005.07.027

Pereira, R., Valente, L. M. P., Sousa-Pinto, I., and Rema, P. (2012). Apparent nutrient digestibility of seaweeds by rainbow trout (Oncorhynchus mykiss) and Nile tilapia (Oreochromis niloticus). Algal Res. 1, 77-82. doi: 10.1016/j.algal. 2012.04.002

Piñeiro-Vidal, M., Carballas, C. G., Gómez-Barreiro, O., Riaza, A., and Santos, Y. (2008a). Tenacibaculum soleae sp. nov., isolated from diseased sole (Solea senegalensis Kaup). Int. J. Syst. Evol. Microbiol. 58, 881-885. doi: 10.1099/ijs.0. 65539-0

Piñeiro-Vidal, M., Riaza, A., and Santos, Y. (2008b). Tenacibaculum discolor sp. nov. and Tenacibaculum gallaicum sp. nov., isolated from sole (Solea senegalensis) and turbot (Psetta maxima) culture systems. Int. J. Syst. Evol. Microbiol. 58, 21-25. doi: 10.1099/ijs.0.65397-0

Rawls, J. F., Samuel, B. S., and Gordon, J. I. (2004). Gnotobiotic zebrafish reveal evolutionarily conserved responses to the gut microbiota. Proc. Natl. Acad. Sci. U.S.A. 30, 4596-4601. doi: 10.1073/pnas.0400706101

Ray, A., Ghosh, K., and Ringo, E. (2012). Enzyme-producing bacteria isolated from fish gut: a review. Aquacult. Nutr. 18, 465-492. doi: 10.1111/j.1365-2095.2012. 00943.x

Reverter, M., Bontemps, N., Lecchini, D., Banaigs, B., and Sasal, P. (2014). Use of plant extracts in fish aquaculture as an alternative to chemotherapy: current status and future perspectives. Aquaculture 433, 50-61. doi: 10.1016/ j.aquaculture.2014.05.048

Rico, R., Tapia-Paniagua, S. T., Martinez-Manzanares, E., Balebona, M. C., and Moriñigo, M. A. (2008). Characterization of Vibrio harveyi strains recovered from diseased farmed Senegalese sole (Solea senegalensis). J. Appl. Microbiol. 105, 752-760. doi: 10.1111/j.1365-2672.2008.03 786.X

Rico, R. M., Tejedor-Junco, M. T., Tapia-Paniagua, S. T., Alarcón, F. J., Mancera, J. M., López-Figueroa, F., et al. (2016). Influence of the dietary inclusion of Gracilaria cornea and Ulva rigida on the biodiversity of the intestinal microbiota of Sparus aurata juveniles. Aquacult. Int. 26, 965-984. doi: 10.1007/ s10499-015-9964-X

Rideout, J. R., He, Y., Navas-Molina, J. A., Walters, W. A., Ursell, L. K., Gibbons, S. M., et al. (2014). Subsampled open-reference clustering creates consistent, comprehensive OTU definitions and scales to billions of sequences. PeerJ 2:e545. doi: $10.7717 /$ peerj.545

Ringø, E., Sperstad, S., Myklebust, R., Refstie, S., and Krogdahl, A. (2006). Characterisation of the microbiota associated with intestine of Atlantic cod (Gadus morhua L.). The effect of fish meal, standard soybean meal and a bioprocessed soybean meal. Aquaculture 261, 829-841. doi: 10.1016/j. aquaculture.2006.06.030

Ringø, E., Zhou, Z., Gonzalez Vecino, J. L., Wadsworth, S., Romero, J., Krogdahl, A., et al. (2016). Effect of dietary components on the gut microbiota of aquatic animals: a never-ending story? Aquacult. Nutr. 22, 219-282. doi: 10.1111/anu.12346

Romero, J., and Navarrete, P. (2006). 16S rDNA-based analysis of dominant bacterial populations associated with early life stages of coho salmon (Oncorhynchus kisutch). Microb. Ecol. 51, 422-430. doi: 10.1007/s00248-0069037-9

Romero, J., Ringo, E., and Merrifield, D. (2014). "The gut microbiota of fish," in Aquaculture Nutrition: Gut Health, Probiotics and Prebiotics, First Edn, eds D. Merrifield and E. Ringø (Hoboken, NY: John Wiley and Sons, Ltd.).

Sáez, M. I., Martínez, T., and Alarcón, J. (2013). Effect of dietary inclusion of seaweeds on intestinal proteolytic activity of juvenile sea bream, Sparus aurata. Int. Aquafeed 16, 38-40.

Salinas, I., Díaz-Rosales, P., Cuesta, A., Meseguer, J., Chabrillón, M., Moriñigo, M. A., et al. (2006). Effect of heat-inactivated fish and non-fish derived probiotics on the innate immune parameters of a teleost fish (Sparus aurata L.). Vet. Immunol. Immunopathol. 111, 279-286. doi: 10.1016/j.vetimm.2006. 01.020

Segata, N., Izard, J., Waldron, L., Gevers, D., Miropolsky, L., Garrett, W. S., et al. (2011). Metagenomic biomarker discovery and explanation. Genome Biol. 12:R60. doi: 10.1186/gb-2011-12-6-r60
Semova, I., Carten, J. D., Stombaugh, J., Mackey, L. C., Knight, R., Farber, S. A., et al. (2012). Microbiota regulate intestinal absorption and metabolism of fatty acids in the zebrafish. Cell Host Microb. 12, 277-288. doi: 10.1016/j.chom.2012. 08.003

Silva, M., Vieira, L., Almeida, A. P., and Kijjoa, A. (2013). The marine macroalgae of the genus Ulva: chemistry, biological activities and potential applications. Oceanography 1:101. doi: 10.4172/2332-2632.100 0101

Småge, S. B., Brevik, Ø. J., Duesund, H., Ottem, K. F., Watanabe, K., and Nylund, A. (2016a). Tenacibaculum finnmarkense sp. nov., a fish pathogenic bacterium of the family Flavobacteriaceae isolated from Atlantic salmon. Antonie Van Leeuwenhoek 109, 273-285. doi: 10.1007/s10482-0150630-0

Småge, S. B., Frisch, K., Brevik, O. J., Watanabe, K., and Nylund, A. (2016b). First isolation, identification and characterisation of Tenacibaculum maritimum in Norway, isolated from diseased farmed sea lice cleaner fish Cyclopterus lumpus L. Aquaculture 464, 178-184. doi: 10.1016/j.aquaculture.2016. 06.030

Sugita, H., and Ito, Y. (2006). Identification of intestinal bacteria from Japanese flounder (Paralichthys olivaceus) and their ability to digest chitin. Lett. Appl. Microbiol. 43, 336-342. doi: 10.1111/j.1472-765X.2006.01 943.x

Sullam, K. E., Essinger, S. D., Lozupone, C. A., O’Connor, M. P., Rosen, G. L., Knight, R., et al. (2012). Environmental and ecological factors that shape the gut bacterial communities of fish: a meta-analysis. Mol. Ecol. 21, 3363-3378. doi: 10.1111/j.1365-294X.2012.05552.x

Tapia-Paniagua, S. T., Chabrillón, M., Díaz-Rosales, P., García de la Banda, I., Lobo, C., Balebona, M. C., et al. (2010). Intestinal microbiota diversity of the flat fish Solea senegalensis (Kaup, 1858) following probiotic administration. Microb. Ecol. 60, 310-319. doi: 10.1007/s00248-0109680-Z

Tapia-Paniagua, S. T., Lobo, C., Moreno-Ventas, X., García de la Banda, I., Moriñigo, M. A., and Balebona, M. C. (2014a). Probiotic supplementation influences the diversity of the intestinal microbiota during early stages of farmed senegalese sole (Solea senegalensis, Kaup 1858). Mar. Biotechnol. 16, 716-728. doi: 10.1007/s10126-014-9588-6

Tapia-Paniagua, S. T., Vidal, S., Lobo, C., Prieto-Álamo, M. J., Jurado, J., Cordero, H., et al. (2014b). The treatment with the probiotic Shewanella putrefaciens Pdp11 of specimens of Solea senegalensis exposed to high stocking densities to enhance their resistance to disease. Fish Shellfish Immunol. 41, 209-221. doi: 10.1016/j.fsi.2014.08.019

Tapia-Paniagua, S. T., Vidal, S., Lobo, C., García de la Banda, I., Esteban, M. A., Balebona, M. C., et al. (2015). Dietary administration of the probiotic SpPdp11: effects on the intestinal microbiota and immune-related gene expression of farmed Solea senegalensis treated with oxytetracycline. Fish Shellfish Immunol. 46, 449-458. doi: 10.1016/j.fsi.2015.07.007

Valente, L. M. P., Gouveia, A., Rema, P., Matos, J., Gomes, E. F., and Pinto, I. S. (2006). Evaluation of three seaweeds Gracilaria bursa-pastoris, Ulva rigida and Gracilaria cornea as dietary ingredients in European sea bass (Dicentrarchus labrax) juveniles. Aquaculture 252, 85-91. doi: 10.1016/j.aquaculture.2005. 11.052

Verner-Jeffreys, D. W., Shields, R. J., Bricknell, I. B., and Birkbeck, T. H. (2003). Changes in the gut-associated microflora during the development of Atlantic halibut (Hippoglossus hippoglossus L.) larvae in three British hatcheries. Aquaculture 219, 21-42. doi: 10.1016/S0044-8486(02)00 $348-4$

Vizcaíno, A. J., Mendes, S. I., Varela, J. L., Ruiz-Jarabo, I., Rico, R., Figueroa, F. L., et al. (2015). Growth, tissue metabolites and digestive functionality in Sparus aurata juveniles fed different levels of macroalgae, Gracilaria cornea and Ulva rigida. Aquac. Res. 47:32243238.

Vizcaíno, A. J., Rodiles, A., López, G., Sáez, M.-I., Herrera, M., Hachero, I., et al. (2018). Growth performance, body composition, and digestive functionality of Senegalese sole (Solea senegalensis Kaup, 1858) juveniles fed diets including microalgae freeze-dried biomass. Fish Physiol. Biochem. 44, 661-677. doi: 10.1007/s10695-018-0462-8

Wang, A. R., Ran, C., Ringo, E., and Zhou, Z. G. (2018). Progress in fish gastrointestinal microbiota research. Rev. Aquacult. 10, 1-15. doi: 10.1111/raq. 12191 
Wassef, E. A., El-Sayed, A. F. M., Kandeel, K. M., and Sakr, E. M. (2005). Evaluation of Pterocla dia and Ulva meals as additives to gilthead seabream Sparus aurata diets. Egypt. J. Aquat. Res. 31, 321-332.

Xing, M., Hou, Z., Yuan, J., Liu, Y., Qu, Y., and Liu, B. (2013). Taxonomic and functional metagenomic profiling of gastrointestinal tract microbiome of the farmed adult turbot (Scophthalmus maximus). FEMS Microbiol. Ecol. 86, 432-443. doi: 10.1111/1574-6941.12174

Ye, L., Amberg, J., Chapman, D., Gaikowski, M., and Liu, W. T. (2014). Fish gut microbiota analysis differentiates physiology and behavior of invasive Asian carp and indigenous American fish. ISME J. 8, 541-551. doi: 10.1038/ismej. 2013.181

Yildirim, Ö., Ergün, S., Yaman, S., and Türker, A. (2009). Effects of two seaweeds (Ulva lactuca and Enteromorpha linza) as a feed additive in diets on growth performance, feed utilization, and body composition of rainbow trout (Oncorhynchus mykiss). Kafkas Univ. Vet. Fak. Derg. 15, 455-460.

Yoon, S. H., Ha, S. M., Kwon, S., Lim, J., Kim, Y., Seo, H., et al. (2017). Introducing EzBioCloud: a taxonomically united database of $16 \mathrm{~S}$ rRNA and whole genome assemblies. Int. J. Syst. Evol. Microbiol. 67, 1613-1617. doi: 10.1099/ijsem.0. 001755
Yúfera, M., and Darias, M. J. (2007). Changes in the gastrointestinal pH from larvae to adult in Senegal sole (Solea senegalensis). Aquaculture 267, 94-99. doi: 10.1016/j.aquaculture.2007.02.009

Zorrilla, I., Arijo, S., Chabrillón, M., Díaz-Rosales, P., Martínez-Manzanares, E., Balebona, M. C., et al. (2003). Vibrio species isolated from diseased farmed sole, Solea senegalensis (Kaup), and evaluation of the potential virulence role of their extracellular products. J. Fish Dis. 26, 103-108. doi: 10.1046/j.1365-2761.2003. 00437.x

Conflict of Interest Statement: The authors declare that the research was conducted in the absence of any commercial or financial relationships that could be construed as a potential conflict of interest.

Copyright (c) 2019 Tapia-Paniagua, Fumanal, Anguís, Fernández-Díaz, Alarcón, Moriñigo and Balebona. This is an open-access article distributed under the terms of the Creative Commons Attribution License (CC BY). The use, distribution or reproduction in other forums is permitted, provided the original author(s) and the copyright owner(s) are credited and that the original publication in this journal is cited, in accordance with accepted academic practice. No use, distribution or reproduction is permitted which does not comply with these terms. 